\title{
Arginine-containing surfactant-like peptides: interaction with lipid membranes and antimicrobial activity
}

Article

Castelletto, V., Barnes, R. H., Karatzas, K.-A., Edwards-Gayle, C. J. C., Greco, F., Hamley, I. W., Rambo, R., Seitsonen, J. and Ruokolainen, J. (2018) Arginine-containing surfactant-like peptides: interaction with lipid membranes and antimicrobial activity. Biomacromolecules, 19 (7). pp. 2782-2794. ISSN 1525-7797 doi: https://doi.org/10.1021/acs.biomac.8b00391 Available at https://centaur.reading.ac.uk/77258/

It is advisable to refer to the publisher's version if you intend to cite from the work. See Guidance on citing.

To link to this article DOI: http://dx.doi.org/10.1021/acs.biomac.8b00391

Publisher: American Chemical Society

All outputs in CentAUR are protected by Intellectual Property Rights law, including copyright law. Copyright and IPR is retained by the creators or other copyright holders. Terms and conditions for use of this material are defined in the End User Agreement. 


\section{CentAUR}

Central Archive at the University of Reading

Reading's research outputs online 


\title{
Arginine-Containing Surfactant-Like Peptides: Interaction with Lipid Membranes and Antimicrobial Activity
}

\author{
Valeria Castelletto, ${ }^{* \dagger}{ }^{\dagger}$ Ruth H. Barnes, ${ }^{\dagger}$ Kimon-Andreas Karatzas, ${ }^{\dagger}$ Charlotte J. C. Edwards-Gayle, ${ }^{\dagger}$ \\ Francesca Greco, ${ }^{\dagger}$ Ian W. Hamley,* ${ }^{\dagger}{ }^{\dagger}$ Robert Rambo, Jani Seitsonen, ${ }^{\S}$ and Janne Ruokolainen ${ }^{\S}$ \\ ${ }^{\dagger}$ School of Chemistry, Food Biosciences and Pharmacy, University of Reading, Whiteknights, Reading RG6 6AD, United Kingdom \\ ${ }^{\ddagger}$ Diamond Light Source, Harwell Science and Innovation Campus, Didcot, Oxfordshire OX11 0DE, United Kingdom \\ ${ }^{\S}$ Department of Applied Physics, Aalto School of Science, P.O. Box 15100, FI-00076 Aalto, Finland
}

\section{Supporting Information}

\begin{abstract}
The activity of antimicrobial peptides stems from their interaction with bacterial membranes, which are disrupted according to a number of proposed mechanisms. Here, we investigate the interaction of a model antimicrobial peptide that contains a single arginine residue with vesicles containing model lipid membranes. The surfactant-like peptide $\mathrm{Ala}_{6}$ - $\operatorname{Arg}\left(\mathrm{A}_{6} \mathrm{R}\right)$ is studied in the form where both termini are capped $\left(\mathrm{CONH}-\mathrm{A}_{6} \mathrm{R}-\mathrm{NH}_{2}, \mathrm{capA}_{6} \mathrm{R}\right)$ or uncapped $\left(\mathrm{NH}_{2}-\mathrm{A}_{6} \mathrm{R}\right.$ $\left.\mathrm{OH}, \mathrm{A}_{6} \mathrm{R}\right)$. Lipid membranes are selected to correspond to model anionic membranes (POPE/POPG) resembling those in bacteria or model zwitterionic membranes (POPC/DOPC) similar to those found in mammalian cells. Viable antimicrobial

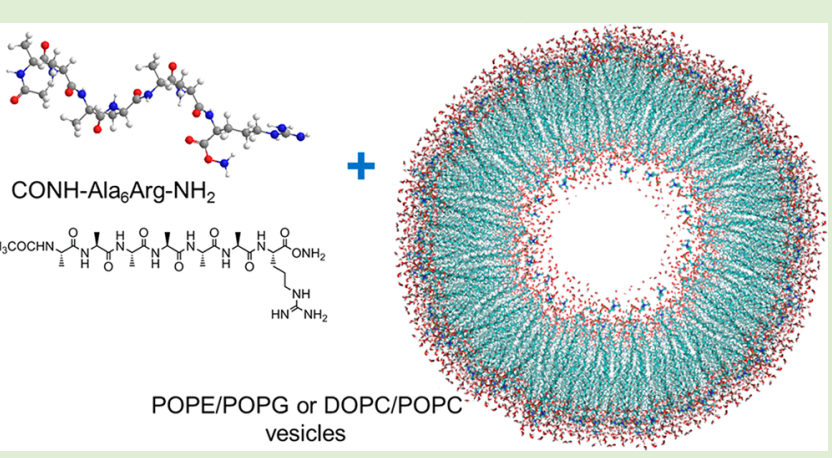
agents should show activity against anionic membranes but not zwitterionic membranes. We find, using small-angle X-ray scattering (SAXS) and cryogenic-TEM (transmission electron microscopy) that, uniquely, cap $\mathrm{A}_{6} \mathrm{R}$ causes structuring of anionic membranes due to the incorporation of the peptide in the lipid bilayer with peptide $\beta$-sheet conformation revealed by circular dichroism spectroscopy (CD). There is a preferential interaction of the peptide with POPG (which is the only anionic lipid in the systems studied) due to electrostatic interactions and bidentate hydrogen bonding between arginine guanidinium and lipid phosphate groups. At a certain composition, this peptide leads to the remarkable tubulation of zwitterionic phosphatidylcholine (PC) vesicles, which is ascribed to the interaction of the peptide with the outer lipid membrane, which occurs without penetration into the membrane. In contrast, peptide $\mathrm{A}_{6} \mathrm{R}$ has a minimal influence on the anionic lipid membranes (and no $\beta$ sheet peptide structure is observed) but causes thinning (lamellar decorrelation) of zwitterionic membranes. We also investigated the cytotoxicity (to fibroblasts) and antimicrobial activity of these two peptides against model Gram positive and Gram negative bacteria. A strong selective antimicrobial activity against Gram positive Listeria monocytogenes, which is an important food-borne pathogen, is observed for cap $\mathrm{A}_{6} \mathrm{R}$. Peptide $\mathrm{A}_{6} \mathrm{R}$ is active against all three studied bacteria. The activity of the peptides against bacteria and mammalian cells is related to the specific interactions uncovered through our SAXS, cryo-TEM, and CD measurements. Our results highlight the exquisite sensitivity to the charge distribution in these designed peptides and its effect on the interaction with lipid membranes bearing different charges, and ultimately on antimicrobial activity.
\end{abstract}

\section{INTRODUCTION}

Multilamellar structures are present in biological systems such as the lipid membranes that comprise the main component of cell walls. Lipid vesicles are often used as simple models of lipid membranes in cell walls.

It is known that antimicrobial peptides restructure bacterial cell membranes, although there are several proposed mechanisms involving different modes of incorporation of peptides into the lipid membrane (to form pores as in the barrel-stave model) or adsorption onto the surface of the membrane (carpet model) with subsequent membrane breakup or the formation of toroidal pores due to peptide-lipid curvature. $^{1-4}$
An important class of antimicrobial peptides are arginine-rich peptides, ${ }^{4}$ which undergo strong interactions with lipid membranes due to electrostatic interactions between the cationic guanidinium group and anionic or zwitterionic charges on phosphate groups in lipids. ${ }^{5,6}$ This can lead to membrane poration and, hence, antimicrobial activity.

In this work we study the interaction of the peptide Ac- $\mathrm{A}_{6} \mathrm{R}$ $\mathrm{NH}_{2}$ peptide $\left(\operatorname{capA}_{6} \mathrm{R} ; \mathrm{A}\right.$ : alanine, $\mathrm{R}$ : arginine) and its uncapped analogue $A_{6} R$ with lipid membranes. These peptides belong to the family of surfactant-like peptides (SLPs), which

Received: March 5, 2018

Revised: $\quad$ May 4, 2018

Published: May 8, 2018 
Scheme 1. Chemical Structures of the Lipids and Peptides Used in This Work

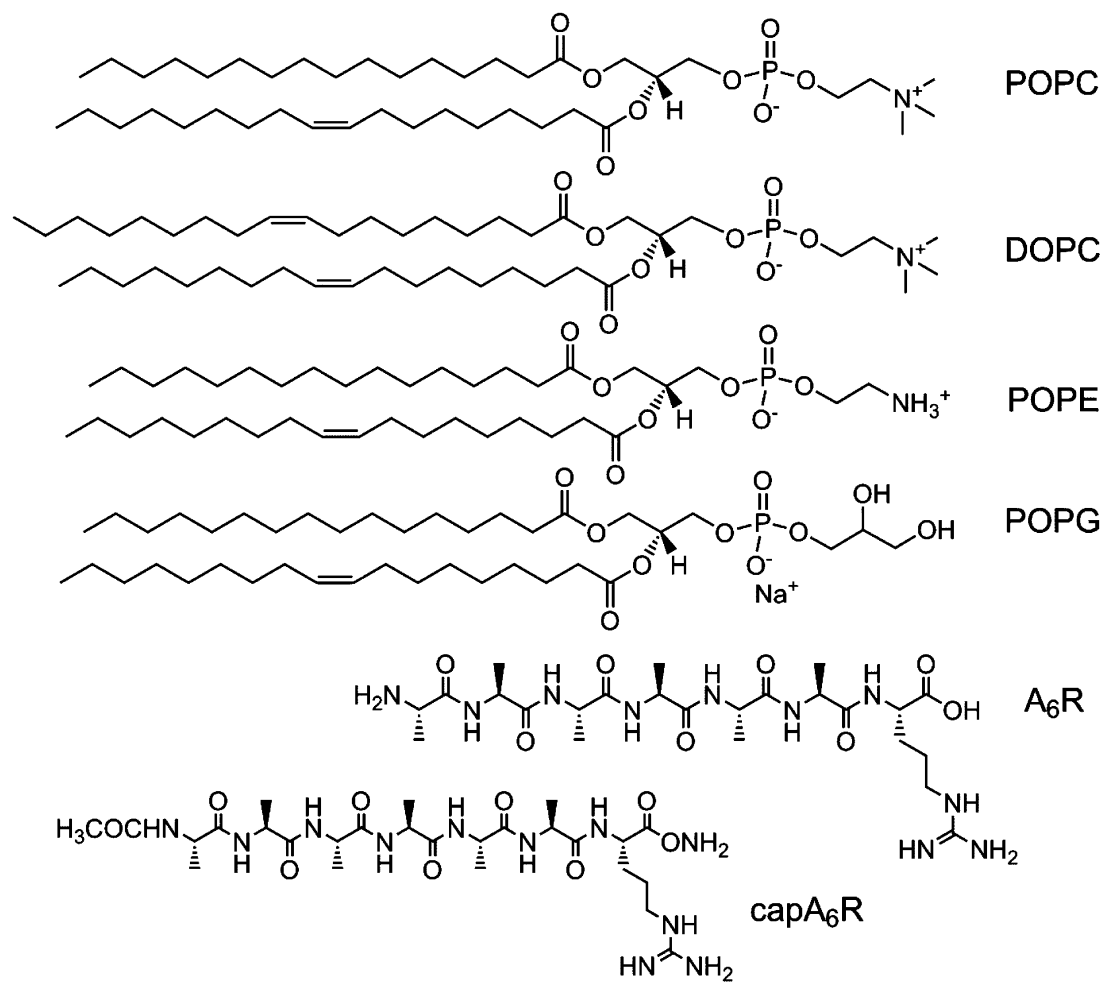

consist of a charged headgroup attached to a hydrophobic sequence. $^{7-11}$ SLPs have great potential in the development of antimicrobial agents due to their simple design and short sequences, along with the potential to display the charged residue at high density on the surface of self-assembled nanostructures, which form at sufficiently high concentration. A diversity of nanostructures has been reported for this class of peptide. ${ }^{7-17}$ In our previous studies, we reported that $\mathrm{A}_{6} \mathrm{~K}$ forms nanotubes in concentrated aqueous solution. ${ }^{12,13}$ In contrast, nanotapes were observed for $\mathrm{A}_{6} \mathrm{H}^{14}$ and nanosheets for $\mathrm{A}_{6} \mathrm{R}$ at low concentration (helical ribbons and nanotubes at high concentration), ${ }^{15}$ nanosheets also being observed for $\mathrm{A}_{6} \mathrm{D} .{ }^{16}$ In another example, the SLP $\mathrm{A}_{6} \mathrm{RGD}$, which incorporates the RGD integrin cell adhesion motif, forms fibrils or vesicles, depending on the concentration in aqueous solution. ${ }^{17}$

Recent work shows that $\mathrm{A}_{6} \mathrm{~K}$ and $\mathrm{A}_{9} \mathrm{~K}$ show antimicrobial activity against Gram-negative E. coli and Gram-positive $S$. aureus, ${ }^{18}$ and that the antibacterial activity was associated with self-assembly (or relative amphiphilicity) into elongated, ${ }^{18}$ since peptide $\mathrm{A}_{3} \mathrm{~K}$, which formed irregular aggregates, exhibited minimal antimicrobial activity against both types of bacteria.

Studying the interaction of antimicrobial peptides (AMPs) with lipid membranes in bacteria and cells opens a path to understand the activity of antimicrobial peptides. This knowledge can be applied to improve therapeutics, as part of the global challenge to overcome emerging antimicrobial resistance (AMR). Antimicrobial peptides, commonly rich in cationic residues (in particular arginine or lysine) and hydrophobic residues, ${ }^{4}$ are potentially powerful tools to combat AMR because they act in a nonspecific way by disrupting bacterial cell membranes, rather than through any specific receptor. $1,2,3,4,19-24$

Here, we investigate the self-assembly of the surfactant-like peptide $A c-A_{6} R-N_{2}\left(\operatorname{capA}_{6} R\right)$ and compare it to that of the uncapped peptide, which was previously reported to form nanosheet structures in dilute aqueous solution, which wrap into helical ribbons and nanotubes at higher concentration. ${ }^{15}$ The uncapped peptide shows promising antimicrobial activity against Gram positive and Gram negative bacteria. ${ }^{25}$ Here, the self-assembly of cap $\mathrm{A}_{6} \mathrm{R}$ is investigated using a combination of circular dichroism (CD), Fourier transform infrared (FTIR) spectroscopy, cryogenic-transmission electron microscopy (cryo-TEM) imaging and small-angle X-ray scattering (SAXS). A critical aggregation concentration (cac) is located through fluorescence assays using a probe sensitive to the formation of $\beta$-sheet fibrils.

We then study the binding of $\operatorname{cap}_{6} \mathrm{R}$ to anionic POPG/ POPE or zwitterionic POPC/DOPC vesicles as model bacterial and mammalian membranes, respectively. ${ }^{26,27}$ POPG indicates 2-oleoyl-1-palmitoyl-sn-glycero-3-phospho-rac-(1-glycerol) sodium salt, POPE denotes 2-oleoyl-1-palmitoyl-sn-glycero-3phosphoethanolamine, DOPC denotes 1,2-dioleoyl-sn-glycero3-phosphocholine, and POPC denotes 2-oleoyl-1-palmitoyl-snglycero-3-phosphocholine. Studies on model membranes enable our understanding of the role of individual lipid components on the function of antimicrobial peptides. ${ }^{28}$ Our choice of model anionic and zwitterionic vesicles is based on the fact that bacterial cell membranes contain significant amounts of phosphatidylethanolamine (PE) and phosphatidylglycerol (PG) lipids. ${ }^{29}$ On the other hand, mammalian cell membranes are generally zwitterionic ${ }^{30}$ and mainly composed of phosphatidylcholines (PCs). ${ }^{26,31}$ Also, bacterial cell membranes incorporate peptidoglycan layers, distinct from mammalian cells. This also enables Gram positive and Gram negative bacteria to be distinguished. Gram positive bacteria have thick cell walls rich in peptidoglycans and, uniquely, teichoic acids. In contrast, Gram negative bacteria have a thin membrane with peptidoglycans located between the cytoplasmic leaflet and 
lipopolysaccharides incorporated in the outer bacterial membrane.

Peptide cap $\mathrm{A}_{6} \mathrm{R}$ is capped at the $\mathrm{N}$-terminus with an acetyl group $\left(\mathrm{CH}_{3} \mathrm{CONH}_{2}\right)$ and is amidated at the $\mathrm{C}$-terminus $\left(\mathrm{CONH}_{2}\right)$ so that the only moiety that can bear charge is the arginine residue. $\mathrm{CD}$ is used to study the modification of the peptide conformation in the presence of lipids. Changes in the lipid membrane due to peptide binding are studied by cryoTEM and SAXS. The latter is a particularly powerful method to determine the ordering of the lamellae within vesicles in situ, averaged over the sample volume.

We previously studied the self-assembly, cytotoxicity and antimicrobial activity of $\mathrm{A}_{6} \mathrm{R}$ in water, and its interaction with model zwitterionic multilamellar vesicles (MLVs) made of DPPC (1,2-dipalmitoyl-sn-glycero-3-phosphocholine). ${ }^{15,25}$ Here we also study the binding of $\mathrm{A}_{6} \mathrm{R}$ to more realistic membrane models, that is, anionic POPG/POPE or zwitterionic POPC/DOPC vesicles to understand the influence of the capped-termini on cap $\mathrm{A}_{6} \mathrm{R}$ binding to lipids.

We investigate the cytotoxicity and antimicrobial properties of capA $_{6} \mathrm{R}$ using model Gram-positive ( $S$. aureus, $L$. monocytogenes) and Gram-negative (E. coli) bacteria. Very strong and selective antimicrobial activity is observed for $L$. monocytogenes for a cap $\mathrm{A}_{6} \mathrm{R}$ concentration where there is a moderate degree of compatibility to human cells. The cytotoxicity and antimicrobial properties of cap $_{6} \mathrm{R}$ are compared to those of the uncapped peptide $A_{6} R$ with free termini. $\mathrm{A}_{6} \mathrm{R}$ bears two ionizable units, as opposed to cap $\mathrm{A}_{6} \mathrm{R}$ with only one ionizable unit. Very distinct behavior is observed comparing the capped and uncapped peptides, with different restructuring of lipid vesicles. This is explained in terms of the subtle and selective electrostatic interactions with anionic or zwitterionic lipids.

\section{EXPERIMENTAL SECTION}

Samples. Peptides $\mathrm{A}_{6} \mathrm{R}$ and $\operatorname{capA}_{6} \mathrm{R}$ (Scheme 1) were custom synthesized by Biomatik (Canada). The peptides were received as TFA salts, the purities were determined by the supplier to be 96.94 and $95.87 \%$, as determined from HPLC (0.1\% TFA in water/ acetonitrile gradient) for $\mathrm{A}_{6} \mathrm{R}$ and cap $_{6} \mathrm{R}$, respectively. Molar masses $M_{\mathrm{w}}=600.68$ and $641.73 \mathrm{Da}$ were measured by electro-spray ionization mass spectroscopy (ESI-MS) analysis for $A_{6} R$ and $\operatorname{cap}_{6} R$, respectively. Lipids 2-oleoyl-1-palmitoyl-sn-glycero-3-phospho-rac-(1glycerol) sodium salt (POPG; $\left.M_{\mathrm{w}}=770.99 \mathrm{Da}\right)$, 2-oleoyl-1-palmitoylsn-glycero-3-phosphoethanolamine (POPE; $\left.M_{\mathrm{w}}=718 \mathrm{Da}\right), 1,2-$ dioleoyl-sn-glycero-3-phosphocholine (DOPC; $\left.M_{\mathrm{w}}=786.11 \mathrm{Da}\right)$, and 2-oleoyl-1-palmitoyl-sn-glycero-3-phosphocholine (POPC; $M_{\mathrm{w}}=$ $760.08 \mathrm{Da}$; Scheme 1) were purchased from Sigma-Aldrich (U.K.) and used as received. Peptides cap $\mathrm{A}_{6} \mathrm{R}$ and $\mathrm{A}_{6} \mathrm{R}$ present a positive charge +1 in water. Lipids POPE, POPC, and DOPC are zwitterionic in water, while lipid POPG has a negative charge -1 in water.

Vesicle Preparation. Vesicles were prepared by the thin layer hydration method, as reported in the literature for hybrid POPE/ POPG vesicles. ${ }^{32}$ Measured quantities of lipids were dissolved in chloroform, dried under a stream of nitrogen and placed in a vacuum chamber for $2 \mathrm{~h}$ in order to remove traces of organic solvent. The lipid film was then resuspended in a weighed quantity of water to obtain 0.5 wt \% lipid, vortexed at $1800 \mathrm{rpm}$ and $55{ }^{\circ} \mathrm{C}$ for $5 \mathrm{~min}$ and left to equilibrate before experiments. Anionic POPG/POPE vesicles were made to provide a POPG molar fraction $\phi_{\mathrm{POPG}}=[\mathrm{POPG}] /([\mathrm{POPG}]$ $+[\mathrm{POPE}])=0.2($ here [] refers to the molar concentration $)$, which corresponds to a POPG/POPE content $27 / 73$ wt \% (e.g., \% POPE = $100 \times$ weightPOPE/weight $(\mathrm{POPE}+\mathrm{POPG}))$. Zwitterionic vesicles were made by mixing POPC and DOPC lipids at a fixed molar fraction of DOPC $\phi_{\text {DOPC }}=[\mathrm{DOPC}] /([\mathrm{POPC}]+[\mathrm{DOPC}])=0.2$, which corresponds to a POPC/DOPC content of $80 / 20 \mathrm{wt} \%$. The vesicles, containing $\phi_{\mathrm{POPG}}$ or $\phi_{\mathrm{DOPC}}$, were always prepared with a fixed total 0.5 wt $\%$ lipid concentration.

For mixed peptide-lipid samples, a weighed quantity of $A_{6} R$ or cap $\mathrm{A}_{6} \mathrm{R}$ powder was added to solutions containing the lipid vesicles described above, to obtain $0.08,0.25$, or 0.5 wt $\% \mathrm{~A}_{6} \mathrm{R}$ or capA $\mathrm{A}_{6} \mathrm{R}$. The mixtures were then vortexed at $1800 \mathrm{rpm}$ and $55^{\circ} \mathrm{C}$ for $5 \mathrm{~min}$ and left to equilibrate before experiments.

Circular Dichroism (CD) Spectroscopy. CD spectra were recorded using a Chirascan spectropolarimeter (Applied Photophysics, U.K.). Solutions were placed in a quartz coverslip cuvette (0.01 or 0.1 $\mathrm{mm}$ thick). Spectra are presented with absorbance $A<2$ at any measured point with a $0.5 \mathrm{~nm}$ step, $1 \mathrm{~nm}$ bandwidth, and $1 \mathrm{~s}$ collection time per step. The CD signal from the water background was subtracted from the $\mathrm{CD}$ data of the sample solutions.

Fourier Transform Infrared (FTIR) Spectroscopy. Spectra were recorded using a Nexus-FTIR spectrometer equipped with a DTGS detector. Samples were measured using an ATR configuration with a PEARL liquid cell. Samples were dissolved in $\mathrm{D}_{2} \mathrm{O}$. Spectra were scanned 128 times over the range of $900-4000 \mathrm{~cm}^{-1}$.

X-ray Diffraction (XRD). Measurements were performed on stalks prepared by drying a drop of solution suspended between the ends of wax-coated capillaries. The stalks were mounted onto a four axis goniometer of an Oxford Diffraction Gemini Ultra instrument. The sample-detector distance was $44 \mathrm{~mm}$. The $\mathrm{X}$-ray wavelength was $\lambda=$ $1.54 \AA$. The wavenumber scale $(q=4 \pi \sin \theta / \lambda$, where $2 \theta$ is the scattering angle) was geometrically calculated. The detector was a Sapphire CCD.

Cryogenic-Transmission Electron Microscopy (Cryo-TEM). Imaging was carried out using a field emission cryo-electron microscope (JEOL JEM-3200FSC), operating at $200 \mathrm{kV}$. Images were taken in bright field mode and using zero loss energy filtering (omega type) with a slit width of $20 \mathrm{eV}$. Micrographs were recorded using a Gatan Ultrascan $4000 \mathrm{CCD}$ camera. The specimen temperature was maintained at $-187^{\circ} \mathrm{C}$ during the imaging. Vitrified specimens were prepared using an automated FEI Vitrobot device using Quantifoil 3.5/1 holey carbon copper grids with a hole size of $3.5 \mu \mathrm{m}$. Just prior to use, grids were plasma cleaned using a Gatan Solarus 9500 plasma cleaner and then transferred into the environmental chamber of a FEI Vitrobot at room temperature and 100\% humidity. Thereafter, $3 \mu \mathrm{L}$ of sample solution was applied on the grid and it was blotted twice for $5 \mathrm{~s}$ and then vitrified in a $1 / 1$ mixture of liquid ethane and propane at temperature of $-180^{\circ} \mathrm{C}$. The grids with vitrified sample solution were maintained at liquid nitrogen temperature and then cryo-transferred to the microscope.

Small-Angle X-ray Scattering (SAXS). Synchrotron SAXS experiments on solutions were performed using BioSAXS robots on beamline BM29 (ESRF, France), on beamline B21 (Diamond Light Source Ltd., U.K.) or on beamline P12 ${ }^{33}$ (EMBL, Germany). SAXS experiments on precipitates or gels were performed on beamline I22 (Diamond Light Source Ltd., U.K.). On beamlines B21, BM29, and P12, solutions were loaded into the 96-well plate of an EMBL BioSAXS robot and then injected via an automated sample exchanger into a quartz capillary $(1.8 \mathrm{~mm}$ internal diameter $)$ in the X-ray beam. The quartz capillary was enclosed in a vacuum chamber in order to avoid air scattering. After the sample was injected in the capillary and reached the X-ray beam, the flow was stopped during the SAXS data acquisition. B21 operated with a fixed camera length $(3.9 \mathrm{~m})$ and fixed energy $(12.4 \mathrm{keV})$. The images were captured using a Pilatus $2 \mathrm{M}$ detector. Data processing (background subtraction, radial averaging) was performed using the dedicated beamline software ScÅtter. BM29 operated with an X-ray wavelength $\lambda=1.03 \AA$ (12 keV). The images were captured using a PILATUS $1 \mathrm{M}$ detector, while data processing was performed using dedicated beamline software ISPYB. Experiments at P12 were done remotely. The station operated with an X-ray wavelength $\lambda=1.24 \AA$. Data was collected using a PILATUS $1 \mathrm{M}$ detector and reduced using ATSAS SASFLOW pipeline software. ${ }^{34,35}$

At I22, precipitates or gels were placed in differential scanning calorimetry (DSC) aluminum pans modified with Teflon windows to enable transmission of the X-ray beam. The sample-to-detector distance was $7.5 \mathrm{~m}$. A Pilatus P3-2 M detector was used to acquire the 
2D SAXS scattering patterns. SAXS data was corrected for the Teflon background scattering. Diffraction from silver behenate was used to calibrate the wavevector scale of the scattering curve. WAXS data was collected using a Pilatus detector. Data processing was performed using software DAWN (Data Analysis Software group, Diamond Light Source Ltd.).

Fluorescence Assays. Thioflavin T (ThT) fluorescence assays were performed to detect amyloid formation by capA $\mathrm{A}_{6} \mathrm{R}$, since it is well-known that ThT fluorescence depends on the formation of amyloid-like structures ( $\beta$-sheet fibrils). ${ }^{36,37}$ For the ThT assay, emission spectra were recorded from 460 to $600 \mathrm{~nm}$ using an excitation wavelength $\lambda_{\text {ex }}=440 \mathrm{~nm}$ for peptide solutions containing $5.0 \times 10^{-3}$ wt $\%$ ThT.

Cytotoxicity Assays. The cytotoxicity of $\mathrm{A}_{6} \mathrm{R}$ and capA $\mathrm{A}_{6} \mathrm{R}$ was examined. In vitro cell culture was conducted using the $161 \mathrm{br}$ (ECACC) human skin fibroblast cell line. Cells were cultured in EMEM (Eagle's Minimum Essential Medium), with $2 \mathrm{mM}$ glutamine, enriched with $15 \%$ fetal bovine serum (FBS), $1 \%$ nonessential amino acids (NEAA), and 1\% antibiotic-antimycotic (Thermoscientific, $100 \times)$. Cells were maintained in a humidified atmosphere of $5 \%$ $\mathrm{CO}_{2}$ at $37^{\circ} \mathrm{C}$.

Cell viability effects were examined using the MTT 3-(4,5dimethylthiazol-2-yl)-2,5-diphenyltetrazolium bromide) assay. $A_{6} R$ and cap $\mathrm{A}_{6} \mathrm{R}$ were dissolved in complete medium. Cells were seeded into a 96-well plate at a seeding density of $4 \times 10^{4}$ cells $/ \mathrm{mL}$, and allowed to adhere for $24 \mathrm{~h}$ in $100 \mu \mathrm{L}$ complete medium. After $24 \mathrm{~h}$, a total volume of $100 \mu \mathrm{L}$ of either complete medium and/or peptide solution was added, to give final peptide concentrations of $0.5,0.25$, $0.1,0.05,0.01$, or $0.005 \mathrm{wt} \%$ peptide. Negative controls of peptide in complete medium with no cells were included.

After $67 \mathrm{~h}$ of incubation, $20 \mu \mathrm{L}$ of MTT ( $0.5 \mathrm{wt} \%$ in PBS) was added to each well plate and allowed to incubate for $5 \mathrm{~h}$ (total of $72 \mathrm{~h}$ incubation). After this, the solutions were removed from the wells and replaced with $100 \mu \mathrm{L}$ DMSO per well in order to dissolve the formazan crystals. Plates were incubated for $30 \mathrm{~min}$, and then analyzed using a UV microplate reader $(\lambda=570 \mathrm{~nm})$. Results are reported $[($ treated cells - negative control $) /($ untreated cells $)] \times 100 .^{38-40}$ The ANOVA and Bonferoni post hoc test were used to determine whether there was statistical significance.

Bacterial Strains and Growth Condition. Experiments were performed with three different microorganisms, namely, Staphylococcus aureus, Listeria monocytogenes, and Escherichia coli. The strains used were a wild-type strain of $S$. aureus previously isolated from ham, ${ }^{41}$ a widely used wild-type strain of L. monocytogenes $\left(\mathrm{LO} 28^{42,43}\right)$, and one of the most widely used E. coli strains (K-12). Stock cultures were stored at $-80{ }^{\circ} \mathrm{C}$ in $7 \%(\mathrm{v} / \mathrm{v})$ DMSO (Sigma-Aldrich, Dorset, U.K.). Prior to experiments, stock cultures of $S$. aureus and L. monocytogenes were streaked onto brain heart infusion (BHI) agar (LAB M, Lancashire, U.K.), while those of E. coli were streaked onto Lysogeny Broth (LB) agar (Oxoid, U.K.) and incubated overnight at $37^{\circ} \mathrm{C}$

Preparation of Cell Suspensions. Three colonies from these cultures were then transferred to $3 \mathrm{~mL}$ of sterile Tryptone soy broth (TSB) supplemented with $0.3 \%(\mathrm{w} / \mathrm{v})$ yeast extract (TSBY; Oxoid,

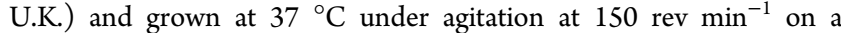
Gallenkamp orbital shaker for $24 \mathrm{~h}$. Subsequently, $20 \mathrm{~mL}$ of selected broth TSB broth was inoculated with the previously prepared overnight cultures up to $1 \%$ and grown at $37{ }^{\circ} \mathrm{C}$ under an agitation of $150 \mathrm{rev} \mathrm{min}^{-1}$ for a further $24 \mathrm{~h}$. These cultures were used for the subsequent experiments.

The viability of the cultures was assessed before use by serially diluting in Maximum Recovery Diluent (MRD, Oxoid) and plating onto nutrient agar. Cultures were transferred into $50 \mathrm{~mL}$ falcon tubes (VWR U.K.) and cells were harvested by centrifugation at $9000 \mathrm{rpm}$ and $4{ }^{\circ} \mathrm{C}$ for $10 \mathrm{~min}$ in an Eppendorf 5804 Centrifuge. The supernatant was then discarded and the pellet was resuspended in 1.5 $\mathrm{mL}$ ice chilled phosphate-buffered saline (PBS). A total of $20 \mu \mathrm{L}$ of this solution was then transferred in $200 \mu \mathrm{L}$ of $0.5 \mathrm{wt} \%$ capA $_{6} \mathrm{R}$ or 0.5 wt $\% \mathrm{~A}_{6} \mathrm{R}$ solution prepared in sterile water. Control solutions were made by inoculating $200 \mu \mathrm{L}$ of sterile water with $20 \mu \mathrm{L}$ of the PBS suspended culture. Solutions were then vortexed for $3 \mathrm{~s}$, and samples were taken at $0,30,60$, and $1440 \mathrm{~min}$. A total of $100 \mu \mathrm{L}$ of the peptide culture solution was then serially diluted in $\mathrm{MRD}$, and subsequently, $10 \mu \mathrm{L}$ of each dilution was plated onto plate count agar (PCA) and incubated at $37^{\circ} \mathrm{C}$ for $24 \mathrm{~h}$ before colony counting.

\section{RESULTS}

We first examined the self-assembly of cap $_{6} \mathrm{R}$ in water, performing fluorescence spectroscopy, CD, FTIR, XRD, SAXS, and cryo-TEM experiments. Results are displayed in Figure 1.
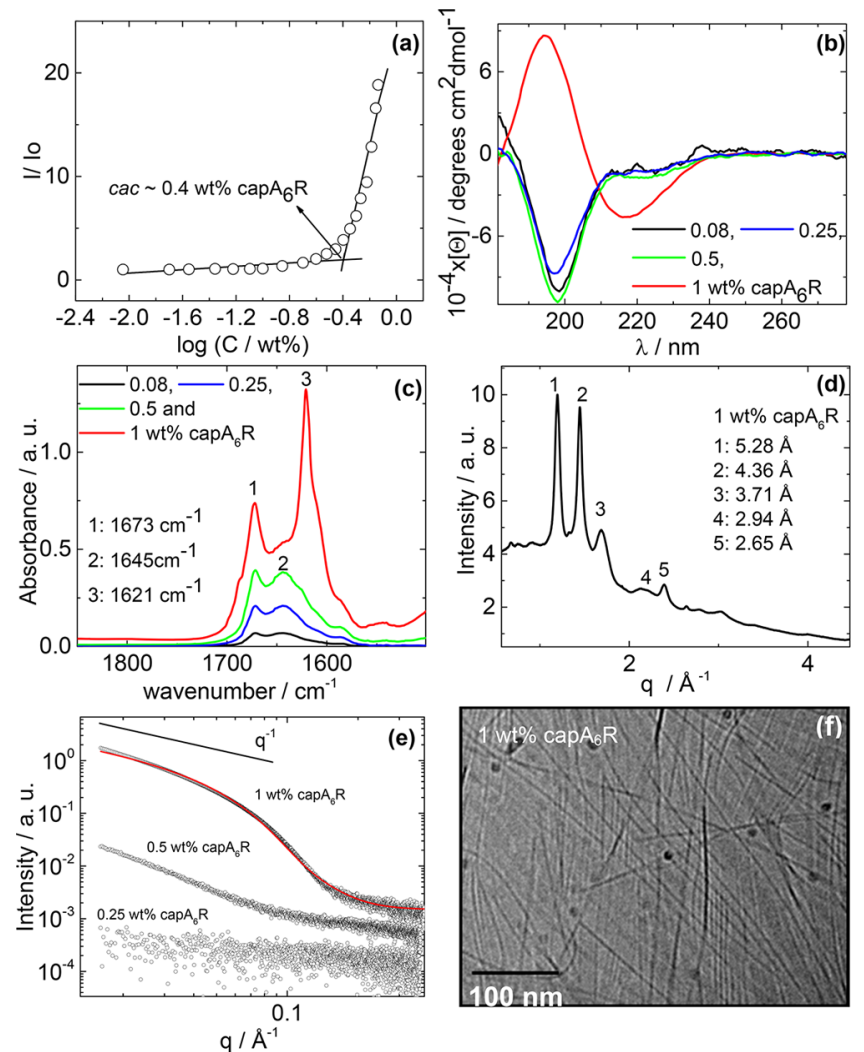

Figure 1. (a) cac results from ThT assays on capA $\mathrm{A}_{6} \mathrm{R}$. (b) $\mathrm{CD}$, (c) FTIR, (d) XRD, (e) SAXS, and (f) cryo-TEM images measured for capA $_{6} \mathrm{R}$ below and above the cac $\sim 0.4$ wt $\%$ capA $_{6} \mathrm{R}$, determined in (a).

Fluorescence assays using the dye Thioflavin $\mathrm{T}(\mathrm{ThT})$ were performed to determine the critical aggregation concentration of cap $\mathrm{A}_{6} \mathrm{R}$. Figure 1a plots the fluorescence emission intensity maximum for samples containing cap $\mathrm{A}_{6} \mathrm{R}$ dissolved in $5 \times 10^{-3}$ wt \% ThT (I), normalized by the fluorescence emission maximum for a sample containing only $5 \times 10^{-3} \mathrm{wt} \%$ ThT $\left(I_{\mathrm{o}}\right)$. A discontinuity in the fluorescence intensity ratio $\left(\mathrm{I} / \mathrm{I}_{\mathrm{o}}\right)$ as a function of $\operatorname{capA}_{6} \mathrm{R}$ concentration shows that the peptide selfassembles into $\beta$-sheets, for concentrations higher than $c a c \sim$ 0.4 wt $\% \operatorname{capA}_{6} \mathrm{R}$ (Figure 1a), lower than $c a c \sim 1.4$ wt $\%$ for $\mathrm{A}_{6} \mathrm{R}$ previously determined by us. ${ }^{15}$ This is consistent with the increase in the hydrophobicity of the peptide as a result of capping the termini.

Later in the manuscript, the peptide concentrations for the study of cap $\mathrm{A}_{6} \mathrm{R}$ binding to model anionic or zwitterionic membranes $\left(0.08,0.25\right.$, or $\left.0.5 \mathrm{wt} \% \operatorname{cap}_{6} \mathrm{R}\right)$ were chosen in increasing order; the highest cap $\mathrm{A}_{6} \mathrm{R}$ concentration causing macroscopic phase separation (sample precipitation) at $\phi_{\mathrm{POPG}}$ $=0.2+0.5$ wt $\% \operatorname{capA}_{6} \mathrm{R}$. 
The CD spectra for $0.08-0.5$ wt $\% \operatorname{capA}_{6} \mathrm{R}$ (Figure $1 \mathrm{~b}$ ), show a minimum at $190 \mathrm{~nm}$, corresponding to a disordered structure. ${ }^{10,11}$ In contrast, the $\mathrm{CD}$ spectrum for 1 wt $\%$ cap $\mathrm{A}_{6} \mathrm{R}$ shows a deep maximum at $190 \mathrm{~nm}$ along with a shallow minimum at $223 \mathrm{~nm}$, a signature of a $\beta$-sheet structure. ${ }^{10,11}$

The FTIR data for $0.08-0.5 \mathrm{wt} \% \mathrm{capA}_{6} \mathrm{R}$ in Figure $1 \mathrm{c}$ show a band centered at $1645 \mathrm{~cm}^{-1}$, corresponding to a disordered structure, ${ }^{44}$ together with a peak at $1673 \mathrm{~cm}^{-1}$ due to bound TFA counterions. ${ }^{45-48}$ At 1 wt $\% \operatorname{capA}_{6} \mathrm{R}$, the FTIR band at $1645 \mathrm{~cm}^{-1}$ becomes very weak compared to a sharp peak at $1621 \mathrm{~cm}^{-1}$ related to the $\beta$-sheet structure of the self-assembled peptide. ${ }^{44,49}$ Notably, both CD and FTIR seem less sensitive than the ThT fluorescence to the formation of $\beta$-sheet structures at concentrations higher than $c a c \sim 0.4$ wt $\%$ capA $_{6} \mathrm{R}$.

The XRD spectrum for 1 wt $\% \operatorname{cap}_{6} R$ in Figure $1 \mathrm{~d}$ resembles that previously reported by us for 17 wt $\% A_{6} R$. In analogy to our previous XRD pattern indexation, ${ }^{15}$ we assign reflections in Figure 1d correspond to the packing of the polyalanine $\beta$-sheets (5.28 $\AA$ ) and intrasheet spacings (4.36, 3.71, 2.94, and $2.65 \AA$ ).

Solutions containing 0.08 and 0.25 wt $\%$ cap $_{6} \mathrm{R}$ provided a very poor SAXS signal, due to their low concentration (e.g., Figure 1e). The statistics is improved for $0.5 \mathrm{wt} \% \operatorname{capA}_{6} \mathrm{R}$, but a successful analytical fitting of the SAXS data could only be performed for 1 wt $\%$ capA $_{6} \mathrm{R}$ (Figure 1e). Nevertheless, a dependence of $\sim q^{-1}$ in the SAXS curve at very low angles, signals the formation of fibers in the solution ${ }^{50}$ (Figure 1e). The full lines in Figure 1e correspond to fits of the SAXS data for 1 wt $\% \operatorname{capA}_{6} \mathrm{R}$ using a long cylindrical shell model, using the software SASfit. ${ }^{51,52}$ The parameters of the model are the core radius $R$ (with polydispersity $\Delta R$ ), the shell thickness $D_{\mathrm{r}}$, and the scattering length density of the core, shell, and solvent $\eta_{\text {core }} \eta_{\text {shell, }}$ and $\eta_{\text {solv }}$. The parameters extracted from the fitting are listed in Table $S 1$. The values, $R \pm \Delta R=(18 \pm 10) \AA$ and $D_{\mathrm{r}}=4.5 \AA$, indicate that the cylinder core has a radius similar to the length of the cap $\mathrm{A}_{6}$ sequence $=22.4 \AA$ ( in a parallel $\beta$-sheet is $3.2 \AA^{53}$ ), while the external shell has a thickness similar to the size of the arginine headgroup.

Figure $1 \mathrm{f}$ shows a cryo-TEM image of a sample containing 1 wt $\%$ capA $_{6} \mathrm{R}$. The image shows the formation of long fibers, $\sim(3.5 \pm 0.7) \mathrm{nm}$ in diameter. The thickness of the fibers is close to the diameter $2 \times\left(D_{\mathrm{r}}+R\right)=(4.5 \pm 2.0) \mathrm{nm}$ of the fibrils estimated from the SAXS parameters listed in Table S1.

Our results show that capping the C-terminus of the $\mathrm{A}_{6} \mathrm{R}$ peptide lowers the cac concentration from 1.4 to $0.4 \mathrm{wt} \%$ peptide and allows for peptide self-assembly into long fibers at 1 wt $\%$ capA $_{6} \mathrm{R}$. We did not observe the formation of ultrathin sheets or peptide nanotubes, previously reported for $A_{6} R$ solutions. ${ }^{15}$ The reduced electrostatic interactions in cap $_{6} R$ favor the self-assembly into fibrils with a $\beta$-sheet structure, at concentrations higher than the cac.

Having examined the self-assembly of cap $\mathrm{A}_{6} \mathrm{R}$ in water, we will study the interaction of $\operatorname{capA}_{6} \mathrm{R}$ with model anionic or zwitterionic membranes represented by POPG/POPE or POPC/DOPC vesicles, respectively. Results will be compared with those obtained for $A_{6} R$ interacting with similar model membranes. Table S2 lists the samples studied. Mostly all samples were cloudy in appearance (but stable, with no evidence of precipitation). The texture of sample $\phi_{\mathrm{POPG}}=0.2+$ 0.25 wt $\%$ capA $_{6} \mathrm{R}$ was slightly grainy, while precipitation eventually occurred for $\phi_{\mathrm{POPG}}=0.2+0.5 \mathrm{wt} \% \operatorname{capA}_{6} \mathrm{R}$. The latter sample presented phase separation as a white precipitate and a transparent supernatant (Table S2). As mentioned above, we prepared samples spanning $\operatorname{cap}_{6} \mathrm{R}$ concentrations such that the higher peptide concentration used in this work, 0.5 wt \%, is determined as the peptide concentration causing macroscopic precipitation for any of the mixed lipid/peptide samples (Table $\mathrm{S} 2)$; in this case, $\phi_{\mathrm{POPG}}=0.2+0.5 \mathrm{wt} \% \mathrm{capA}_{6} \mathrm{R}$.

The interaction of $\operatorname{cap}_{6} \mathrm{R}$ with anionic and zwitterionic vesicles was first studied by SAXS. Figure 2a shows the SAXS

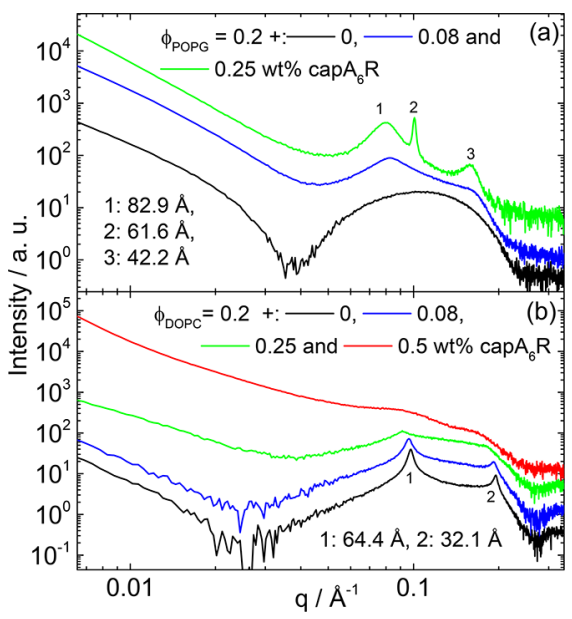

Figure 2. SAXS data measured for vesicles with (a) $\phi_{\mathrm{POPG}}=0.2$ and (b) $\phi_{\text {DOPC }}=0.2$, mixed with $0.08,0.25$, or 0.5 wt $\%$ capA $_{6} R$. SAXS data has been multiplied by an arbitrary factor in order to enable the visualization of the data.

data measured for solutions containing $\phi_{\mathrm{POPG}}=0.2+0,0.08$, or 0.25 wt \% capA $\mathrm{A}_{6} \mathrm{R}$. Figure $\mathrm{S} 1$ shows the SAXS and WAXS data measured for $\phi_{\mathrm{POPG}}=0.2+0.5$ wt $\%$ capA $_{6} \mathrm{R}$. The gel point of cap $\mathrm{A}_{6} \mathrm{R}$ is at $\sim 8 \mathrm{wt} \%$ peptide. Data corresponding to a gel containing $\phi_{\mathrm{POPG}}=0.2+8.5$ wt $\%$ capA $_{6} \mathrm{R}$ is included in Figure $S 1$ only as a reference.

Figure $2 \mathrm{~b}$ shows the SAXS curves measured for solutions containing $\phi_{\mathrm{DOPC}}=0.2+0,0.08,0.25$, or 0.5 wt $\%$ capA $_{6} \mathrm{R}$. The spacings $2 \pi / q_{\mathrm{o}}\left(q_{\mathrm{o}}=\right.$ peak position $)$ measured from the SAXS curves in Figures 2 and S1a are listed in Table S3, together with the associated layer spacings. In the following notation, layer spacing $d_{1}$ is associated with structures containing only POPE, while layer spacing $d$ is associated with structures involving the mixture of lipids. All the ratios between spacings listed in Table S3 indicate lamellar order for the samples studied in this work.

SAXS data for $\phi_{\mathrm{POPG}}=0.2$ (Figure 2a) shows a broad peak centered at $\sim 0.1 \AA^{-1}$ arising from a single bilayer form factor. This sample it is at the $L_{\beta}$ (ordered gel phase) $/ L_{\alpha}$ (disordered liquid crystal structure) phase coexistence, according to the phase diagram of POPG/POPE vesicles reported in the literature. $^{32}$

The SAXS data for $\phi_{\mathrm{POPG}}=0.2+0.08$ wt $\%$ capA $_{6} \mathrm{R}$ is characterized by two broad peaks at 82.9 and $42.2 \AA$. This order increases for the sample with $\phi_{\mathrm{POPG}}=0.2+0.25$ wt $\%$ capA $_{6} \mathrm{R}$, for which SAXS is characterized by three peaks corresponding to spacings 82.9, 61.6, and $42.2 \AA$ (Figure 2a).

Peaks corresponding to spacings at $(82.9 \pm 1.0) \AA$ and $(42.2$ $\pm 1.0) \AA$ are broad peaks in a positional ratio of $1: 2$ and correspond to a layer spacing $d=82.9 \AA$ (Figure 2a, Table S3). The notably sharper Bragg peak with a spacing $(61.6 \pm 1.0) \AA$ is the same as that previously measured by us for a sample containing $0.5 \mathrm{wt} \% \mathrm{POPE}$ at $20^{\circ} \mathrm{C},{ }^{54}$ and therefore, we assign 
it to the presence of a separate population of POPE bilayers at $\phi_{\text {POPG }}=0.2+0.25$ wt $\% \operatorname{capA}_{6} \mathrm{R}$.

Differential scanning calorimetry (DSC) has been frequently used to investigated demixing of mixed lipid membranes upon loading a charged peptide. For example, DSC was used to investigate the demixing of DPPG/DPPE membranes in the presence of the antimicrobial peptide $\mathrm{K}^{0}-\mathrm{W}^{6}-\mathrm{Hyal},{ }^{55}$ or the demixing of POPE/cardiolipin membranes upon binding of antibacterial peptides derived from Human Lactoferricin. ${ }^{56}$ The melting temperature $T_{\mathrm{m}}$ of POPG is $-2{ }^{\circ} \mathrm{C}$, very close to the melting point of ice, and our DSC measurements on POPG/ POPE vesicles containing $\operatorname{capA}_{6} \mathrm{R}$ were unsuccessful because the melting endotherm of the POPG was screened by the ice melting endotherm. We therefore assign the presence of a separate population of POPE bilayers based on the evidence given by SAXS results (spacing $61.6 \AA$ in Figure $2 \mathrm{a}$ ).

In the case of the sample $\phi_{\mathrm{POPG}}=0.2+0.5 \mathrm{wt} \%$ capA $_{6} \mathrm{R}$ (Figure S1a), the SAXS from the supernatant does not present any particular feature and corresponds to monomers. The SAXS data measured for the precipitate of $\phi_{\mathrm{POPG}}=0.2+0.5 \mathrm{wt}$ $\%$ capA $_{6} \mathrm{R}$ (Figure $\mathrm{S} 1 \mathrm{a}$ ) presents peaks corresponding to 83.9, 42.2, and $28.6 \AA$ (layer spacing $d=83.9 \AA$ ) and spacings 61.4 and $31.1 \AA$ (layer spacing $d_{1}=61.4 \AA$ ) are consistent with lamellar order (Table S3, all peak spacings have an uncertainty of $\pm 1.0 \AA$ ). In particular, as discussed before, the cell parameter $d_{1}=61.4 \AA$ denotes the formation of a population rich in POPE bilayers.

The SAXS data for $\phi_{\mathrm{POPG}}=0.2+8.5$ wt $\%$ capA $_{6} \mathrm{R}$ (Figure $\mathrm{S} 1 \mathrm{a}$ ) is dominated by the scattering from the peptide fibrils making the hydrogel, although the spacing $=63.4 \AA$ denotes the existence of POPE lamellae rich-domains. Spacings 82.9 or 83.9 $\AA$, measured for samples below the capA $\mathrm{R}_{6} \mathrm{R}$ gel point (Table S3), are not present for $\phi_{\mathrm{POPG}}=0.2+8.5 \mathrm{wt} \%$ capA $_{6} \mathrm{R}$, where the peptide is self-assembled in a compact network of fibers. We can conclude that spacings 82.9 or $83.9 \AA$ spacings originate from cap $\mathrm{A}_{6} \mathrm{R}$ monomers binding to the $\mathrm{POPE} / \mathrm{POPG}$ membrane.

The WAXS data in Figure S1b displays two reflections at 4.4 and $4.2 \AA$ for the precipitate $\phi_{\mathrm{POPG}}=0.2+0.08 \mathrm{wt} \% \mathrm{capA}_{6} \mathrm{R}$ and one reflection at $4.23 \AA$ for the gel $\phi_{\mathrm{POPG}}=0.2+8.5 \mathrm{wt} \%$ cap $\mathrm{A}_{6} \mathrm{R}$ (reflection at $4.4 \AA$ appears as a shoulder in the WAXS curve). Spacings at 4.2 and $4.23 \AA$ arise from the POPE, and are very close to the average separation of $4.3 \AA$ for the POPE lipid chains in the all-trans configuration of the $\mathrm{L} \beta$ phase. ${ }^{32,57}$ The spacing at $4.4 \AA$ is characteristic of the cap $\mathrm{A}_{6} \mathrm{R} \beta$-sheet structure (Figure 1d).

Overall, Figures $2 \mathrm{a}$ and $\mathrm{S} 1$ show that progressive addition of cap $A_{6} R$ to POPG/POPE vesicles leads to the stacking of the lipid bilayers into multilamellar vesicles. However, concentrations of peptide equal or higher than $0.25 \mathrm{wt} \% \mathrm{capA}_{6} \mathrm{R}$ lead to POPE phase separation.

Figure $2 \mathrm{~b}$ shows that $\mathrm{POPC} / \mathrm{DOPC}$ vesicles, present a multilamellar structure at $20{ }^{\circ} \mathrm{C}$ with a cell parameter $d=64.4$ $\AA^{54}$ The SAXS signal of POPC/DOPC MLVs becomes increasingly screened by the form factor of a peptide fiber upon progressive addition of cap $_{6} \mathrm{R}$ to the system (Figure $2 \mathrm{~b}$ ).

The nanostructure of the solutions in Figure 2 was further analyzed through the fitting of the SAXS data to models for the form factor and structure factor of a lamellar structure. Details of the model ${ }^{58}$ are provided in the Supporting Information. We only fitted the samples without rich POPE lamellar domains. Fits to the SAXS data in Figure 2 are displayed along with the experimental data in Figure S2. Parameters extracted from the fitting are listed in Table S4. Figure S3 shows the electron density distribution across the bilayers, calculated from the parameters listed in Table S4.

Results obtained from the fitting of the SAXS data describe the bilayer correlation induced upon addition of $\operatorname{capA}_{6} \mathrm{R}$ to $\phi_{\mathrm{POPG}}=0.2$ vesicles. The distance between lipid head groups in the $\phi_{\mathrm{POPG}}=0.2$ bilayer, $l_{\mathrm{H}}=47 \AA$, increases to $l_{\mathrm{H}}=51.8 \AA$ for $\phi_{\text {POPG }}=0.2+0.08$ wt $\% \operatorname{capA}_{6} \mathrm{R}$ (Table S4 and Figure S3). This increase is due to the insertion of $\operatorname{cap}_{6} \mathrm{R}$ in the POPG/ POPE bilayer. The addition of 0.08 wt $\%$ peptide to $\phi_{\mathrm{POPG}}=$ 0.2 also increases the length of correlation from 0 to 2 bilayers $(N=2$ in Table S4).

Similarly, the fitting of the SAXS data describes the decorrelation of bilayers induced upon addition of $\operatorname{capA}_{6} \mathrm{R}$ to $\phi_{\text {DOPC }}=0.2$ vesicles. The distance between lipid head groups in the $\phi_{\mathrm{DOPC}}=0.2$ bilayer is $l_{\mathrm{H}}=47.1 \AA$ and remains nearly constant for $\phi_{\mathrm{DOPC}}=0.2$ mixed with $0.08,0.025$, or 0.5 wt $\%$ cap $\mathrm{A}_{6} \mathrm{R}$. However, the length of correlation of the bilayers decreases from $N=8$ to $N=2.3$ by adding $0.5 \mathrm{wt} \%$ capA $_{6} \mathrm{R}$ to $\phi_{\mathrm{POPG}}=0.2$ (Table S4).

As mentioned above, the extended length of the cap $\mathrm{A}_{6} \mathrm{R}$ molecule as $\sim 22.4 \AA$. For the mixtures with $\phi_{\mathrm{POPG}}=0.2$, an increase in $4 \AA$ for $2 z_{\mathrm{H}}$ upon adding peptide indicates that the peptide is nearly fully inserted inside the POPG/POPE membrane. This configuration is probably driven by electrostatic interactions between the arginine residue in $\operatorname{capA}_{6} \mathrm{R}$ and the phosphate group in POPG, as well as the formation of bidentate hydrogen bonds between the arginine guanidinium group and the phosphate group. ${ }^{5,6}$ Attractive interactions between the peptide and the lipid bilayer are not present for increasing concentrations of capA $_{6} \mathrm{R}$ mixed with $\phi_{\mathrm{DOPC}}=0.2$, where $N$ decreases with peptide increasing concentration. It is likely that in the latter case the peptide decorates the surface of the zwitterionic bilayers inducing an electrostatic repulsion that leads to the reduction in $N$ recorded in Table S4.

For zwitterionic membranes, the decorrelation of lipid bilayers is caused by undulations at the surface of the lipid bilayers. Indeed, the Caille parameter $\eta$, which is a measure of the bilayer fluctuations, ${ }^{59}$ increases from 0.5 to 3.1 for a constant $\phi_{\text {DOPC }}=0.2$ with peptide concentration increasing from 0 to 0.5 wt $\%$ capA $_{6} \mathrm{R}$ (Table S4).

Figure 3 shows the $\mathrm{CD}$ data measured for pure 0.08 or 0.25 wt $\% \operatorname{cap}_{6} \mathrm{R}$ and samples containing 0.08 or $0.025 \mathrm{wt} \%$ capA $_{6} \mathrm{R}$ with $\phi_{\mathrm{POPG}}=0.2$ or $\phi_{\mathrm{DOPC}}=0.2$. The $\mathrm{CD}$ spectra for

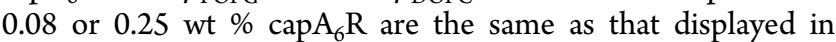
Figure $1 \mathrm{~b}$, consistent with a disordered structure, and are displayed here as a reference. ${ }^{44}$ A disordered secondary structure is also observed for $\phi_{\mathrm{DOPC}}=0.2+0.08$ or $0.25 \mathrm{wt}$ $\%$ cap $\mathrm{A}_{6} \mathrm{R}$. However, the peptide secondary structure becomes $\beta$-sheet (the spectrum contains broad minimum just below 220 $\mathrm{nm})^{44}$ for samples containing $\phi_{\mathrm{POPG}}=0.2+0.08$ or $0.25 \mathrm{wt} \%$ capA $_{6} \mathrm{R}$. This indicates that interaction between cap $_{6} \mathrm{R}$ and POPE/POPG membrane orders the peptide into a $\beta$-sheet structure. The intermolecular hydrogen bonding needed for $\beta$ sheet formation is favored by the insertion of cap $\mathrm{A}_{6} \mathrm{R}$ inside the POPE/POPG membrane according to Scheme S2, where electrostatic interactions and bidentate hydrogen bond formation drive association between the arginine residue and the lipid headgroup.

Stabilization and changes in a peptide structure, driven by the interaction of a peptide with a negatively charged lipid membrane, have already been reported in the literature. For example, the structure adopted by the peptide $\alpha$-melanocyte 


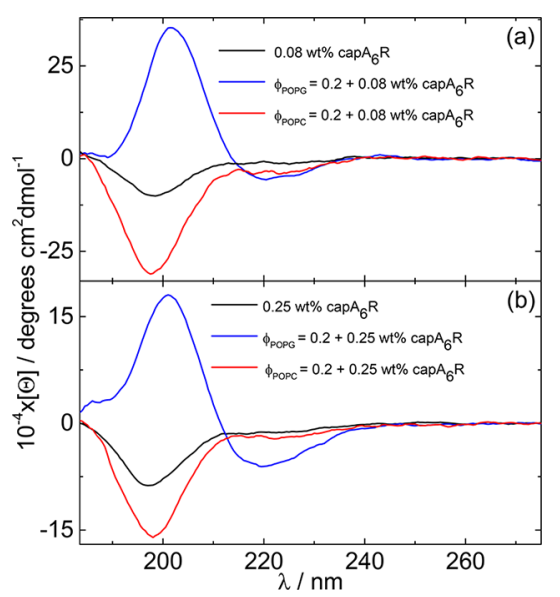

Figure 3. CD data measured for samples containing pure (a) $0.08 \mathrm{wt}$ $\%$ or (b) $0.25 \mathrm{wt} \%$ capA $_{6} \mathrm{R}$ or mixtures of the peptide with vesicles containing $\phi_{\mathrm{POPG}}=0.2$ or $\phi_{\mathrm{DOPC}}=0.2$.

$(\alpha-\mathrm{MSH})$ when it is inserted in a negatively charged binary membrane (DMPC/DMPG or DMPC/DMPA) ${ }^{60}$ is likely to influence the peptide biological activity, but it is different from the structure of $\alpha$-MSH in solution.

The nanostructures of the lipid/peptide mixtures were also studied by cryo-TEM. Inspecting all cryo-TEM images we were able to classify vesicles according to three types shown in Figure 4, along with representative examples: (i) simple thin wall vesicles, (ii) thin wall vesicles with internal structure, i.e. internal compartmentalization, (iii) multilamellar vesicles with uncorrelated layers and typically (but not necessarily) internal compartmentalization, (iv) type (iii) vesicles joined by an elongated layered structure. Classification (i-iv) is modified from that introduced in ref 32 for POPG/POPE vesicles in the absence of peptide and extends to POPC/DOPC vesicles studied in this work. Table S3 summarizes vesicle morphologies identified by cryo-TEM, along with the summary of the SAXS data features discussed above. Figures 5-7 and Figure S4 show representative cryo-TEM images.
A repeat distance $d_{\text {cryo }}=(95 \pm 12) \AA$ can be measured for vesicles at $\phi_{\mathrm{POPG}}=0.2+0.25 \mathrm{wt} \% \mathrm{capA}_{6} \mathrm{R}$ (Table S3 and Figure 5f), corresponding to the cell parameter $d=82.9 \AA$ in the SAXS curve (Figure 2a).

Layer spacings $d_{\text {cryo }}=(62 \pm 0.1)$ and $d_{\text {cryo }}=(67.9 \pm 4.2) \AA$, measured in the cryo-TEM images for $\phi_{\mathrm{DOPC}}=0.2+0$ and 0.08 wt $\%$ capA $\mathrm{A}_{6} \mathrm{R}$, respectively (Table S3, Figure 6, and Figure $S 4)$, correspond to the lamellar cell parameter in Figure $3 \mathrm{~b}(d=$ 64.4 $\AA$, Table S3). These repeat distances can be measured at the walls of the vesicles (Figure 6) or in the elongated lamellar structures joining vesicles (inset Figure 6). These remarkable tubular structures resemble previously observed lipid tubule structures, which are observed in response to gradients in environmental parameters such as temperature and $\mathrm{pH}^{61,62}$ the formation of which is ascribed to a surface tension arising from an asymmetry in the surface area of inner and outer membrane surfaces ("leaflets"). ${ }^{63,64}$ The same mechanism has been proposed to explain the structure of other nonspherical cell structures such as those of red blood cells. We propose that here, the tubule structure is formed due to the decorrelation between the vesicle inner and outer lamellae induced by the interaction of cap $\mathrm{A}_{6} \mathrm{R}$ with the zwitterionic lipids in the outer vesicle surface.

A spacing between membranes of $d_{\text {cryo }}=(214 \pm 26) \AA$, measured for $\phi_{\text {DOPC }}=0.2+0.25$ wt $\%$ capA $_{6} \mathrm{R}$ (Figure $7 \mathrm{a}$ ), does not correspond to a regular repeat distance, and can be associated with the progressive decorrelation of the bilayers observed in the SAXS data (Figure 2b). The cryo-TEM image in Figure $7 \mathrm{~b}$ is consistent with the SAXS curve displayed in Figure $2 \mathrm{~b}$ for $\phi_{\mathrm{DOPC}}=0.2+0.5 \mathrm{wt} \% \mathrm{capA}_{6} \mathrm{R}$, which contains a major contribution from a peptide fibril form factor.

The interaction of $\mathrm{A}_{6} \mathrm{R}$ with POPE/POPG and POPC/ DOPC vesicles was studied by SAXS to understand the influence of the capped termini on the interaction of cap $\mathrm{A}_{6} \mathrm{R}$ with the vesicles. SAXS intensity profiles are displayed in Figure S5a,b; SAXS spacings are listed in Table S3, together with their corresponding $d$-spacing ratio and cell parameter. Control SAXS data for 0.5 wt $\% \mathrm{~A}_{6} \mathrm{R}$, displayed in Figure $\mathrm{S6}$, does not show any particular feature that could influence the SAXS data
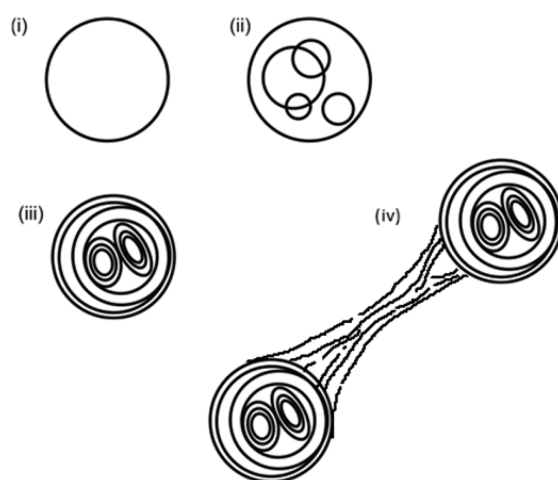

(a)

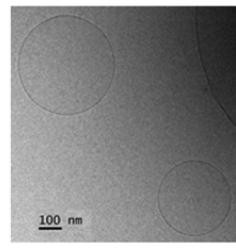

(b)
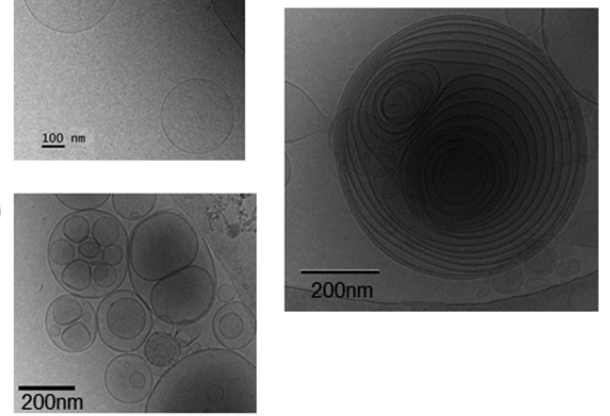

(c)

(d)

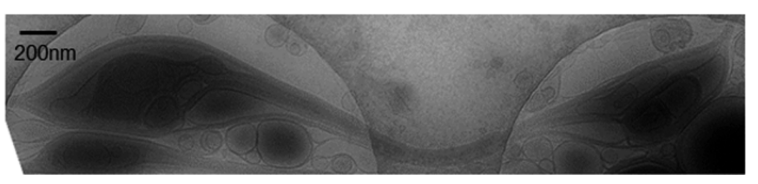

Figure 4. Classification of vesicle types. (i) Thin wall vesicles with no internal structure, (ii) compartmentalized thin wall vesicles, (iii) multilayer vesicles with uncorrelated layers and compartmentalization, (iv) type (iii) vesicles joined together by layered tubule structure. Typical cryo-TEM images for the three types (a) $\phi_{\mathrm{POPG}}=0.2+0.25 \mathrm{wt} \% \mathrm{~A}_{6} \mathrm{R}$ (type (i)), (b) $\phi_{\mathrm{DOPC}}=0.2+0.25$ wt $\% \mathrm{~A}_{6} \mathrm{R}$ (type (ii)), (c) $\phi_{\mathrm{DOPC}}=0.2+0.25$ wt $\%$ capA $_{6} \mathrm{R}$ (type (iii)), and (d) $\phi_{\text {DOPC }}=0.2+0.08$ wt $\%$ capA $_{6} \mathrm{R}$ (type (iv)). 


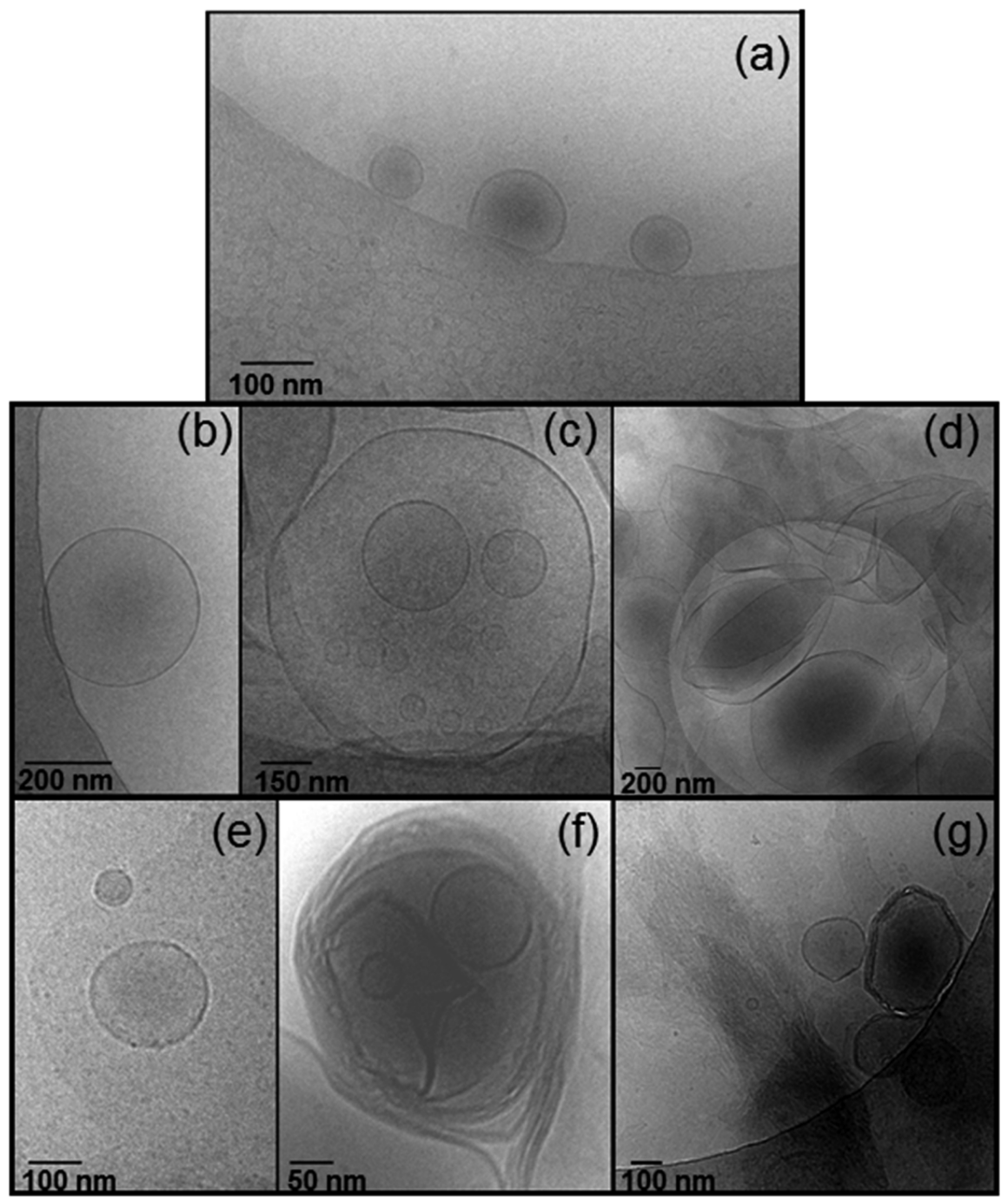

Figure 5. Cryo-TEM images for $\phi_{\mathrm{POPG}}=0.2$ mixed with (a) 0 , (b-d) 0.08 , or $(\mathrm{e}-\mathrm{g}) 0.25$ wt $\%$ capA $\mathrm{A}_{6}$.

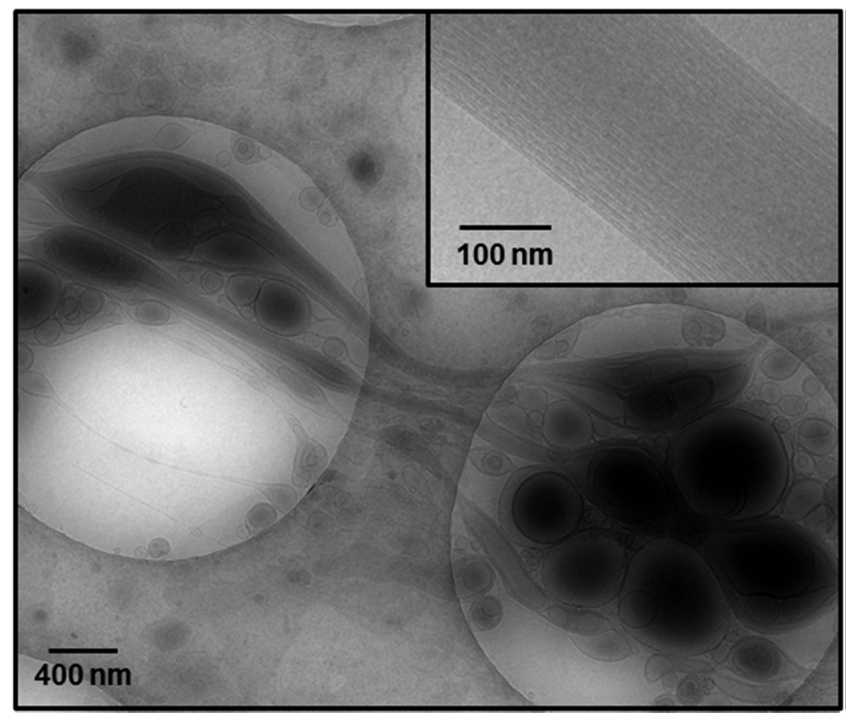

Figure 6. Cryo-TEM image for $\phi_{\mathrm{DOPC}}=0.2$ mixed with $0.08 \mathrm{wt} \%$ cap $_{6} \mathrm{R}$. The inset shows a detail of the elongated layered structure joining some of the vesicles.

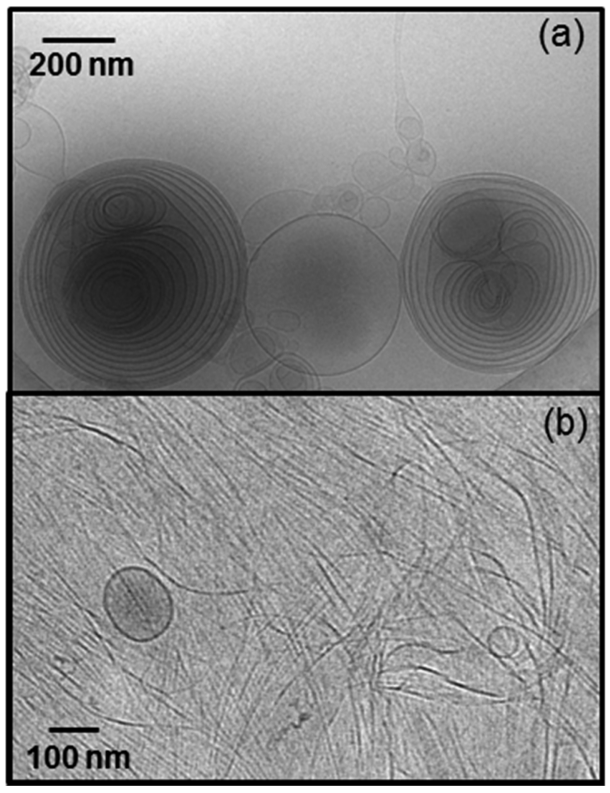

Figure 7. Cryo-TEM image for $\phi_{\mathrm{DOPC}}=0.2$ mixed with (a) 0.25 or (b) 0.5 wt $\%$ capA $_{6} \mathrm{R}$. 
in Figure S5 (SAXS for 0.08 and $0.25 \mathrm{wt} \% \mathrm{~A}_{6} \mathrm{R}$ has been omitted from Figure S6 due to its weak scattering signal).

Figure $\mathrm{S} 5$ a shows that progressive addition of $\mathrm{A}_{6} \mathrm{R}$ to POPG/ POPE vesicles leads to a transition of a small fraction of vesicles from a unilamellar to a multilamellar structure, denoted by the spacing at $65.9 \AA^{32}$ The multilamellar order with bilayer spacing $82.9 \AA$, measured for samples containing cap $\mathrm{A}_{6} \mathrm{R}$ in Figure $3 a$, is not present in Figure $S 5$ a. In contrast to cap $A_{6} R$, $A_{6} R$ is not incorporated into the POPG/POPE bilayer. We suggest that the insertion of $\operatorname{cap}_{6} \mathrm{R}$ in the POPG/POPE membrane is favored by the increase in the hydrophobicity of the peptide as a result of capping the termini.

The SAXS intensity profiles for $\phi_{\mathrm{DOPC}}=0.2+0,0.08,0.25$, or $0.5 \mathrm{wt} \% \mathrm{~A}_{6} \mathrm{R}$ (Figure $\mathrm{S} 5 \mathrm{~b}$ ) are similar to those discussed above in relation to samples containing mixtures of $\operatorname{cap}_{6} \mathrm{R}$ and POPC/DOPC vesicles (Figure 2b), although there is no development of a peptide fibril form factor contribution at 0.5 wt $\% \mathrm{~A}_{6} \mathrm{R}$. Instead, there is a loss of the layer structure factor peaks as the $A_{6} R$ concentration increased and the development of form factor characteristic of unassociated lipid bilayers for $0.08-0.5$ wt $\% \mathrm{~A}_{6} \mathrm{R}$. This result is consistent with the outcome

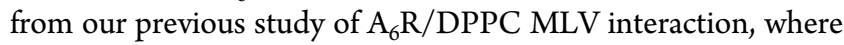
we concluded that addition of $\mathrm{A}_{6} \mathrm{R}$ to the zwitterionic DPPC MLVs eliminates the MLV Bragg peaks from the SAXS profile. $^{25}$

Figure S7 shows the CD data measured for pure 0.08 or 0.25 wt $\% \mathrm{~A}_{6} \mathrm{R}$ and samples containing 0.08 or 0.025 wt $\% \mathrm{~A}_{6} \mathrm{R}$ with $\phi_{\mathrm{POPG}}=0.2$ or $\phi_{\mathrm{DOPC}}=0.2$. The secondary structure of $\mathrm{A}_{6} \mathrm{R}$ in Figure $\mathrm{S} 7 \mathrm{a}, \mathrm{b}$ is consistent with a disordered structure, ${ }^{44}$ independently of being dissolved in water or mixed with anionic or zwitterionic vesicles.

Overall, SAXS and CD results for mixed $\mathrm{A}_{6} \mathrm{R} /$ lipid systems confirm that capping $A_{6} R$ allows insertion of the peptide, selfassembled in a $\beta$-sheet structure, inside POPG/POPE membranes, but this is not observed for $A_{6} R$.

Cryo-TEM was used to confirm the structure of the mixtures of lipids with $\mathrm{A}_{6} \mathrm{R}$. Figure $\mathrm{S} 8$ shows the cryo-TEM images measured for $\phi_{\mathrm{POPG}}=0.2+0.25$ wt $\% \mathrm{~A}_{6} \mathrm{R}$ or $\phi_{\mathrm{DOPC}}=0.2+$ 0.25 wt $\% \mathrm{~A}_{6} \mathrm{R}$. In good agreement with SAXS data, cryo-TEM for $\phi_{\mathrm{DOPC}}=0.2+0.5$ wt \% $\mathrm{A}_{6} \mathrm{R}$ (Figure S9) shows the formation of vesicles with thin walls.

To examine the cytocompatibility of cap $\mathrm{A}_{6} \mathrm{R}$ and $\mathrm{A}_{6} \mathrm{R}$, the viability of the peptide was tested using $161 \mathrm{Br}$ skin fibroblast cells via MTT assays (Figure 8). Peptide capA $\mathrm{R}_{6}$ was tolerated by the cells up to a concentration of $0.01 \mathrm{wt} \%(\sim 75 \%$ viability). But a lower cell viability $<70 \%$ was observed from 0.05 to 0.5 wt $\%$ cap $_{6} \mathrm{R} . \mathrm{A}_{6} \mathrm{R}$ was tolerated by the cells up to a concentration of 0.1 wt $\%$ ( $~ 80.7 \%$ viability), but viability is relatively low for 0.25 and 0.5 wt \% $\mathrm{A}_{6} \mathrm{R}$. Results in Figure 8 show that modifying the termini of $\mathrm{A}_{6} \mathrm{R}$ in cap $\mathrm{A}_{6} \mathrm{R}$ increased the toxicity of the peptide on $161 \mathrm{Br}$ skin fibroblast cells, presumably due to the increased interaction of the arginine residue with the zwitterionic PC lipids in the cell membranes, consistent with the SAXS and cryo-TEM data presented here.

The antimicrobial activity of the cap $\mathrm{A}_{6} \mathrm{R}$ peptide was studied using one model Gram negative microorganism, E. coli, $^{65}$ and two Gram positive microorganisms, $S$. aureus and $L$. monocytogenes. ${ }^{41,66}$ Microorganisms were treated with $0.5 \mathrm{wt}$ $\% \operatorname{capA}_{6} \mathrm{R}$ or 0.5 wt $\% \mathrm{~A}_{6} \mathrm{R}$.

Figure 9 displays the antimicrobial assays results showing the antimicrobial activity of the cap $\mathrm{A}_{6} \mathrm{R}$ peptide against $S$. aureus, $L$. monocytogenes, and E. coli. An effect of the peptide treatment in the range of $1.8 \mathrm{log}$ reduction of the $\mathrm{CFU} / \mathrm{ml}$ was found against

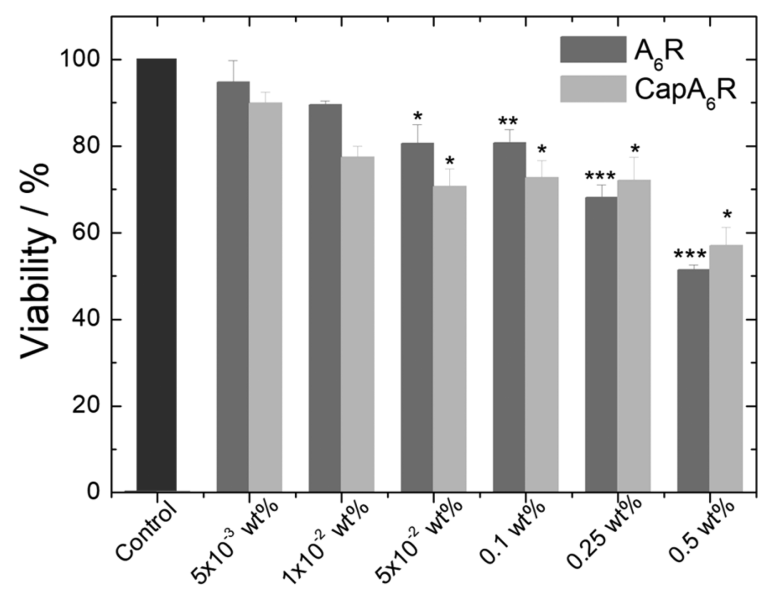

Figure 8. Cell viability profiles for capA $\mathrm{A}_{6} \mathrm{R}$ and $\mathrm{A}_{6} \mathrm{R}$. Error bars: SEM $(n=3) . * p<0.05 ; * * p<0.01 ; * * * p<0.001$

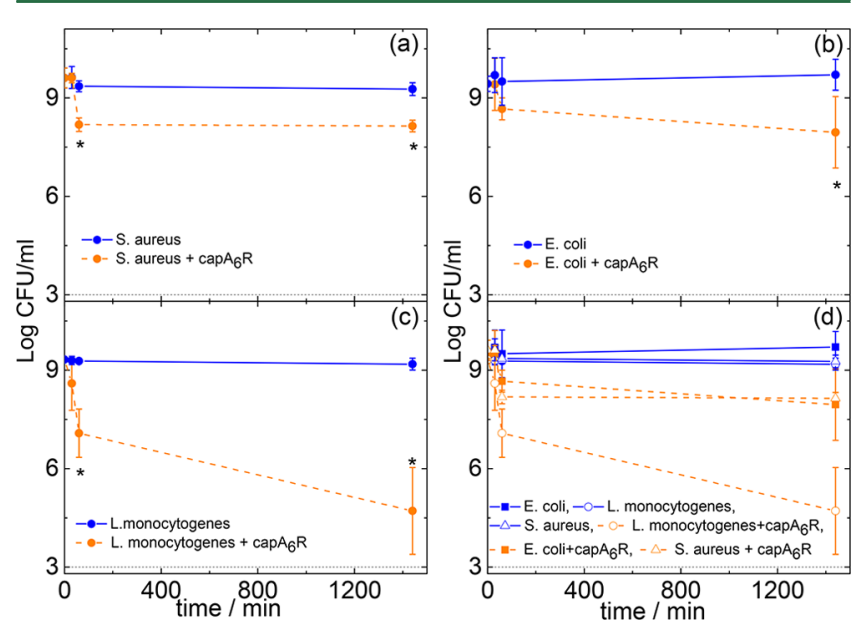

Figure 9. Survival of (a) S. aureus, (b) E. coli, and (c) L. monocytogenes after exposure to the presence or absence of 0.5 wt $\% \operatorname{capA}_{6} \mathrm{R}$. (d) Combined plot of data in $(\mathrm{a})-(\mathrm{c})$. Estimations of the cell numbers (CFU: colony-forming units) at each time point were performed in triplicate (3 biological replicates), while each dilution was plated in duplicate ( 2 technical replicates). Markers represent an average of the measurements performed in triplicate, and error bars represent the standard deviation. The dotted line represents the detection limit of the method. Asterisks denote statistically significant different results comparing the treated and untreated strains at a specific time point as assessed by $t$-test $(P<0.05)$.

E. coli which, however, was not statistically significant. But a statistically significant antimicrobial effect was found with the $L$. monocytogenes and $S$. aureus. In particular, a major effect of 4.7 $\log$ reduction in $\mathrm{CFU} / \mathrm{ml}$ was found with L. monocytogenes, while a less pronounced effect in the range of $1.2 \mathrm{log}$ reduction of the CFU/ml was seen with $S$. aureus. Both of these bacteria are Gram positive, that is, their membrane contains peptidoglycans which bear anionic residues (Glu). ${ }^{67-69}$ In addition, the membranes of Gram positive bacteria contain lipoteichoic acid, which bears negatively charged phosphate groups. ${ }^{67-69}$ We propose that the cationic arginine residue in cap $\mathrm{A}_{6} \mathrm{R}$ interacts with these two types of anionic groups, causing lipid membrane disruption ultimately killing these microbes.

Overall, Figure 9 shows a dramatic effect of cap $\mathrm{A}_{6} \mathrm{R}$ on the numbers of bacteria within the first $1 \mathrm{~h}$. Subsequently, the numbers of $E$. coli and $S$. aureus somehow remained stable 
Scheme 2. Proposed Interaction of $\operatorname{capA}_{6} \mathrm{R}$ with Lipid Bilayers ${ }^{a}$

a)
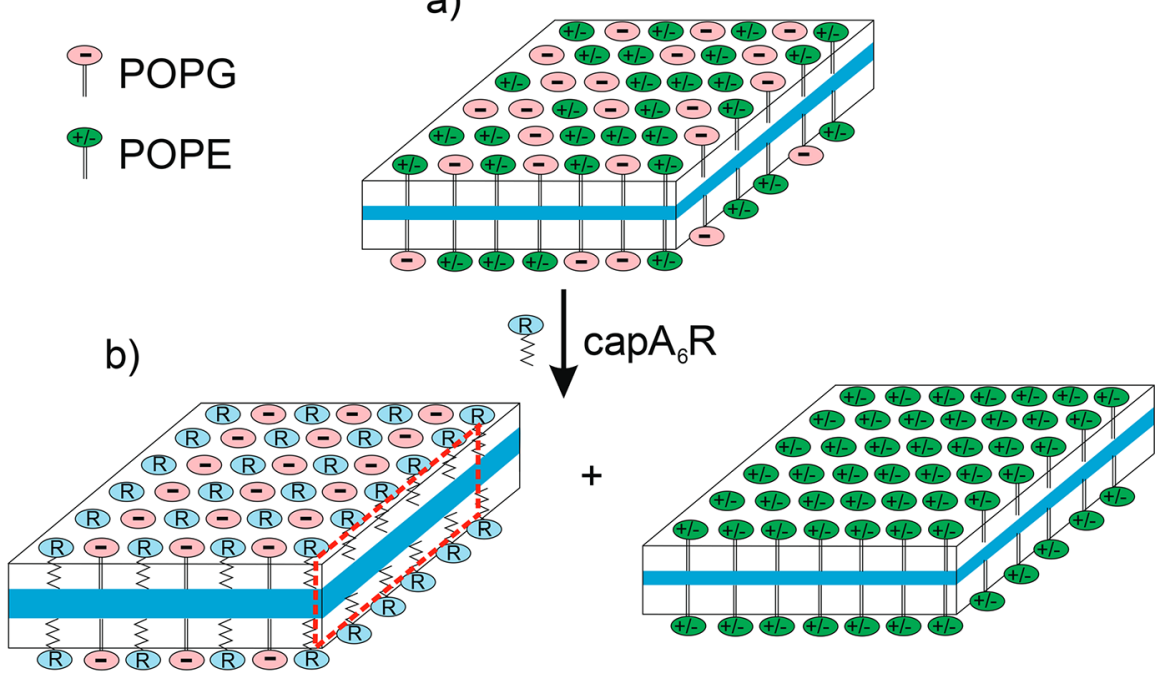

(R)

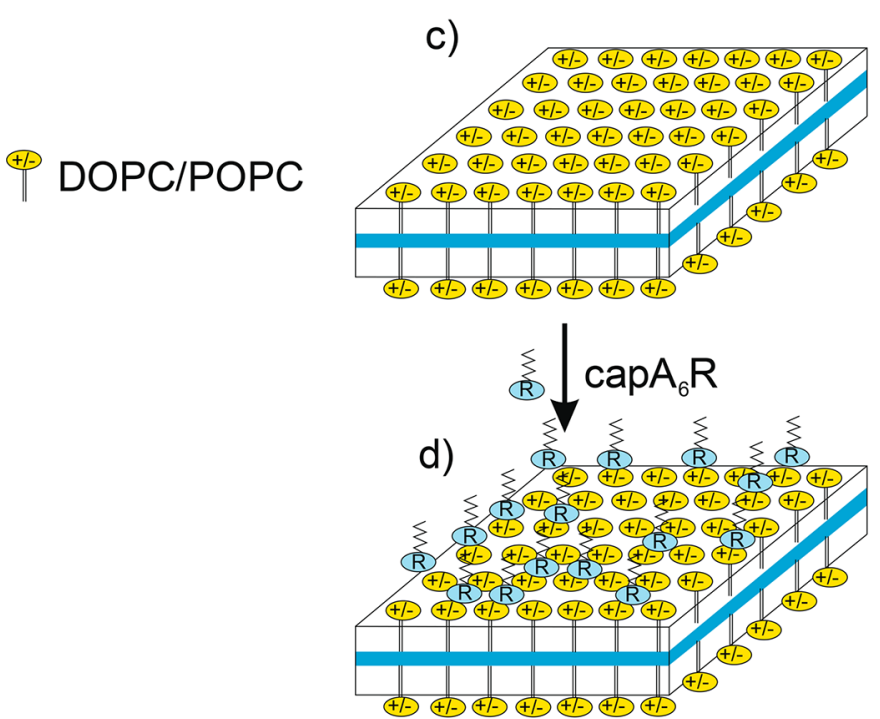

${ }^{a}$ (a) Mixed POPG/POPE bilayers before addition of capA $_{6} \mathrm{R}$. (b) Added capA ${ }_{6} \mathrm{R}$ interacts selectively with POPG, peptide $\beta$-sheet structures (e.g. red dashed sheet) being observed by CD, SAXS shows that POPE forms a distinct bilayer structure (in proposed rafts). (c) Mixed DOPC/POPC bilayer. (d) Added capA $\mathrm{R}$ is absorbed at the surface of the mixed bilayer causing membrane de-correlation. At higher concentration, excess unadsorbed cap $\mathrm{A}_{6} \mathrm{R}$ forms peptide fibrils (e.g. Figure $7 \mathrm{~b}$ ).

within the next $22 \mathrm{~h}$. However, in the case of L. monocytogenes a more pronounced effect was seen within the first $1 \mathrm{~h}$, while the reduction continued for the following $22 \mathrm{~h}$.

Figure S10 displays the antimicrobial assays results showing the antimicrobial activity of the $\mathrm{A}_{6} \mathrm{R}$ peptide against $S$. aureus, $L$. monocytogenes, and E. coli. Figure S10 supports our previous study on the uncapped peptide $A_{6} R$, which included results of preliminary antimicrobial activity assays against $S$. aureus and $E$. coli treated with $0.5 \mathrm{wt} \% \mathrm{~A}_{6} \mathrm{R}^{25}$ We observed that the treatment with $\mathrm{A}_{6} \mathrm{R}$ was more effective against Gram-positive $S$. aureus than $E$. coli; however, the measurements only extended up to $1 \mathrm{~h}$. The data presented here (Figure S10) extend up to $24 \mathrm{~h}$. Comparing cap $\mathrm{A}_{6} \mathrm{R}$ and $\mathrm{A}_{6} \mathrm{R}$ (Figure S11), it is clear that $A_{6} R$ has greater antimicrobial activity against all three studied microbes, including Gram positive and Gram negative bacteria. This shows the strong effect of the charge in the region of the arginine residue at the $\mathrm{C}$ terminus.

\section{SUMMARY AND CONCLUSIONS}

We have used a model peptide system with model lipid membranes to study the interaction of arginine-based antimicrobial peptides with cell and bacterial membranes. The results presented in this work help to understand how to improve the development of selective noncytotoxic antimicrobial peptides as potential therapeutic agents.

Our results show that peptide self-assembly and peptide interaction with lipid membranes can be tuned by subtle adjustment of peptide charge by end-capping. It is remarkable the degree to which vesicle membrane restructuring can be controlled by peptides containing single arginine residues and how this depends on the electrostatic interactions which are enhanced when the termini are capped (as is the hydrophobicity of the peptide).

Scheme 2 summarizes the changes in lipid organization induced by $\operatorname{capA}_{6} \mathrm{R}$ (in monomeric form at low concentration), 
as deduced from our SAXS and CD measurements. The POPG and POPE lipids are mixed in the lipid bilayers. SAXS (Figure 2a) shows the features of unstacked lipid bilayers. Added cap $\mathrm{A}_{6} \mathrm{R}$ interacts selectively with anionic POPG forming peptide $\beta$-sheets (as shown by $\mathrm{CD}$, Figure 3 ) and consistent with SAXS which shows peaks with a spacing significantly expanded from that of the lipid bilayer, which is ascribed to the incorporation of the peptide into the bilayer. At the same time, the SAXS data indicates the presence of a separate population of POPE bilayers (sharper Bragg peak at $61.6 \AA$ in Figure 2a). This is presumably due to phase separation of POPE rafts as indicated in Scheme $2 \mathrm{~b}$. The mixed DOPC/POPC bilayers have a well-correlated multilamellar structure according to SAXS (Figure $2 \mathrm{~b}$ ). Addition of $\mathrm{capA}_{6} \mathrm{R}$ leads to decorrelation of the layers (and at certain compositions of added $\operatorname{capA}_{6} \mathrm{R}$, the formation of tubule structures). We propose that this is due to adsorption of $\operatorname{capA}_{6} \mathrm{R}$ at the outer surface. Electrostatic repulsion between the arginine residues on opposing layers will lead to the observed (via SAXS) decorrelation of the bilayer ordering. Excess added capA ${ }_{6} \mathrm{R}\left(0.5 \mathrm{wt} \%\right.$ capA $\left._{6} \mathrm{R}\right)$ selfassembles into peptide fibrils as shown by cryo-TEM (Figure $7 b$ ). Peptide $\mathrm{A}_{6} \mathrm{R}$ behaves similarly to cap $\mathrm{A}_{6} \mathrm{R}$ in the presence of the DOPC/POPC lipids (see, for example, the SAXS profiles in Figure S5b compared to Figure $2 b$ ), with the difference that there is no contribution from peptide form factor at higher $A_{6} R$ concentration in contrast to capA $A_{6} R$ (for which cryo-TEM also confirms fibril formation). On the other hand, $\mathrm{A}_{6} \mathrm{R}$ does not show significant interactions with the POPG/POPE membranes as shown by the SAXS data in Figure S5a. Only a small fraction of the bilayers become correlated with $0.5 \mathrm{wt} \%$ added $\mathrm{A}_{6} \mathrm{R}$. We propose that the adsorption of cap $\mathrm{A}_{6} \mathrm{R}$ and $\mathrm{A}_{6} \mathrm{R}$ onto the DOPC/POPC bilayers resembles the initial stage of the "carpet mechanism" of adsorption of antimicrobial peptides onto membranes. ${ }^{1,4,19,20}$

Peptide $\mathrm{A}_{6} \mathrm{R}$ shows greater antimicrobial activity than cap $\mathrm{A}_{6} \mathrm{R}$ against all three microbes studied including one Gram negative and two Gram positive bacteria. This occurs despite the weaker interaction of $\mathrm{A}_{6} \mathrm{R}$ with the model anionic membranes which our SAXS, cryo-TEM, and CD studies reveal. This shows that considering the interaction with model lipid membranes alone is insufficient to account for the antimicrobial activity and that interactions with the other components of the outer membrane (peptidoglycan in the case of Gram positive bacteria or lipopolysaccharide in the case of Gram negative bacteria) must be of predominant importance in the interaction with cationic peptides. Nevertheless, our study provides good foundation for future studies to understand less trivial processes involving, for example, membrane permeation. Our work shows that even subtle changes in the charge around a single arginine residue can profoundly influence binding to model lipid membranes, but also that additional interactions with polysaccharides/ glycans must account for the antimicrobial activities.

In future work, the mechanisms of the interactions of cap ${ }_{6} R$ and $\mathrm{A}_{6} \mathrm{R}$ with the model lipid membranes will be further examined at the nanoscale via molecular dynamics simulations.

\section{ASSOCIATED CONTENT}

\section{(5) Supporting Information}

The Supporting Information is available free of charge on the ACS Publications website at DOI: 10.1021/acs.biomac.8b00391.
List of samples studied in this work, list of parameters obtained from SAXS fittings, SAXS data and fittings, CD, cryo-TEM images and antimicrobial assays results (PDF).

\section{AUTHOR INFORMATION}

\section{Corresponding Authors}

*E-mail: v.castelletto@reading.ac.uk.

*E-mail: i.w.hamley@reading.ac.uk.

ORCID ब

Valeria Castelletto: 0000-0002-3705-0162

Ian W. Hamley: 0000-0002-4549-0926

\section{Notes}

The authors declare no competing financial interest.

\section{ACKNOWLEDGMENTS}

This work was supported by EPSRC Platform Grant "Nanostructured Polymeric Materials for Healthcare” (EP/L020599/ 1 to I.W.H.). We are grateful to the EMBL for awarded beamtime on beamline P12 and to Daniel Franke for performing SAXS experiments in remote mode during that beamtime (Ref SAXS 662). We acknowledge the ESRF for beamtime at BM29 (Refs MX1880 and MX1869), and Martha Brennich and Gabrielle Giachin for support during beamtime at BM29. We thank Diamond for beamtime at I22 (Ref SM17902) and B21 (Refs SM15778 and SM17118-1) and Olga Shebanova for help during beamtime on I22. We acknowledge the Central Analysis Facility (University of Reading) and Nick Spencer for assistance with XRD experiments and Jessica Hutchinson for assistance with SAXS measurements.

\section{REFERENCES}

(1) Shai, Y. Mechanism of the binding, insertion and destabilization of phospholipid bilayer membranes by alpha-helical antimicrobial and cell non-selective membrane-lytic peptides. Biochim. Biophys. Acta, Biomembr. 1999, 1462 (1-2), 55-70.

(2) Epand, R. M.; Vogel, H. J. Diversity of antimicrobial peptides and their mechanisms of action. Biochim. Biophys. Acta, Biomembr. 1999, 1462 (1-2), 11-28.

(3) Zasloff, M. Antimicrobial peptides of multicellular organisms. Nature 2002, 415 (6870), 389-395.

(4) Chan, D. I.; Prenner, E. J.; Vogel, H. J. Tryptophan- and argininerich antimicrobial peptides: structures and mechanisms of action. Biochim. Biophys. Acta, Biomembr. 2006, 1758, 1184-1202.

(5) Schmidt, N.; Mishra, A.; Lai, G. H.; Wong, G. C. L. Arginine-rich cell-penetrating peptides. FEBS Lett. 2010, 584 (9), 1806-1813.

(6) Hamley, I. W. Small Bioactive Peptides for Biomaterials Design and Therapeutics. Chem. Rev. 2017, 117, 14015-14041.

(7) Hauser, C. A. E.; Zhang, S. G. Designer self-assembling peptide nanofiber biological materials. Chem. Soc. Rev. 2010, 39 (8), 27802790.

(8) Santoso, S. S.; Vauthey, S.; Zhang, S. Structures, function and applications of amphiphilic peptides. Curr. Opin. Colloid Interface Sci. 2002, 7, 262-266.

(9) Zhao, X. B.; Pan, F.; Xu, H.; Yaseen, M.; Shan, H. H.; Hauser, C. A. E.; Zhang, S. G.; Lu, J. R. Molecular self-assembly and applications of designer peptide amphiphiles. Chem. Soc. Rev. 2010, 39 (9), 34803498.

(10) Hamley, I. W. Self-assembly of amphiphilic peptides. Soft Matter 2011, 7, 4122-4138.

(11) Dehsorkhi, A.; Castelletto, V.; Hamley, I. W. Self-Assembling Amphiphilic Peptides. J. Pept. Sci. 2014, 20, 453-467. 
(12) Castelletto, V.; Nutt, D.; Hamley, I. W.; Bucak, S.; Cenker, C.; Olsson, U. Structure of single-wall peptide nanotubes: in situ flow aligning X-ray diffraction. Chem. Commun. 2010, 46, 6270-6272.

(13) Middleton, D. A.; Madine, J.; Castelletto, V.; Hamley, I. W. Insights into the Molecular Architecture of a Peptide Nanotube Using FTIR and Solid-State NMR Spectroscopic Measurements on an Aligned Sample. Angew. Chem., Int. Ed. 2013, 52, 10537-10540.

(14) Castelletto, V.; Hamley, I. W.; Segarra-Maset, M. D.; Gumbau, C. B.; Miravet, J. F.; Escuder, B.; Seitsonen, J.; Ruokolainen, J. Tuning Chelation by the Surfactant-Like Peptide $\mathrm{A}_{6} \mathrm{H}$ Using Predetermined $\mathrm{pH}$ Values. Biomacromolecules 2014, 15, 591-598.

(15) Hamley, I. W.; Dehsorkhi, A.; Castelletto, V. Self-assembled arginine-coated peptide nanosheets in aqueous solution. Chem. Commun. 2013, 49, 1850-1852.

(16) Hamley, I. W.; Hutchinson, J.; Kirkham, S.; Castelletto, V.; Kaur, A.; Reza, M.; Ruokolainen, J. Nanosheet Formation by an Anionic Surfactant-like Peptide and Modulation of Self-Assembly thorugh Ionic Complexation. Langmuir 2016, 32, 10387-10393.

(17) Castelletto, V.; Gouveia, R. M.; Connon, C. J.; Hamley, I. W.; Seitsonen, J.; Nykanen, A.; Ruokolainen, J. Alanine-rich amphiphilic peptide containing the RGD cell adhesion motif: a coating material for human fibroblast attachment and culture. Biomater. Sci. 2014, 2, 362369.

(18) Chen, C. X.; Pan, F.; Zhang, S. Z.; Hu, J.; Cao, M. W.; Wang, J.; Xu, H.; Zhao, X. B.; Lu, J. R. Antibacterial Activities of Short Designer Peptides: a Link between Propensity for Nanostructuring and Capacity for Membrane Destabilization. Biomacromolecules 2010, 11, 402-411.

(19) Brogden, K. A. Antimicrobial peptides: Pore formers or metabolic inhibitors in bacteria? Nat. Rev. Microbiol. 2005, 3 (3), $238-250$.

(20) Jenssen, H.; Hamill, P.; Hancock, R. E. W. Peptide antimicrobial agents. Clin. Microbiol. Rev. 2006, 19 (3), 491-511.

(21) Hancock, R. E. W.; Sahl, H. G. Antimicrobial and host-defense peptides as new anti-infective therapeutic strategies. Nat. Biotechnol. 2006, 24 (12), 1551-1557.

(22) Taheri-Araghi, S.; Ha, B. Y. Cationic antimicrobial peptides: a physical basis for their selective membrane-disrupting activity. Soft Matter 2010, 6 (9), 1933-1940.

(23) Chen, C. X.; Yang, C.; Chen, Y. C.; Wang, F.; Mu, Q. M.; Zhang, J.; Li, Z. Y.; Pan, F.; Xu, H.; Lu, J. R. Surface Physical Activity and Hydrophobicity of Designed Helical Peptide Amphiphiles Control Their Bioactivity and Cell Selectivity. ACS Appl. Mater. Interfaces 2016, 8 (40), 26501-26510.

(24) Bai, J. K.; Chen, C. X.; Wang, J. X.; Zhang, Y.; Cox, H.; Zhang, J.; Wang, Y. M.; Penny, J.; Waigh, T.; Lu, J. R.; Xu, H. Enzymatic Regulation of Self-Assembling Peptide $\mathrm{A}_{9} \mathrm{~K}_{2}$ Nanostructures and Hydrogelation with Highly Selective Antibacterial Activities. ACS Appl. Mater. Interfaces 2016, 8 (24), 15093-15102.

(25) Dehsorkhi, A.; Castelletto, V.; Hamley, I. W.; Seitsonen, J.; Ruokolainen, J. Interaction between a Cationic Surfactant-like Peptide and Lipid Vesicles and Its Relationship to Antimicrobial Activity. Langmuir 2013, 29 (46), 14246-14253.

(26) Dowhan, W. Molecular basis for membrane phospholipid diversity: Why are there so many lipids? In Annu. Rev. Biochem.; Richardson, C. C., Ed.; Annual Reviews Inc.: California, U.S.A., 1997; Vol. 66, pp 199-232.

(27) Tattrie, N. H.; Bennett, J. R.; Cyr, R. Maximum and minimum values for lecithin classes from various biological sources. Can. J. Biochem. 1968, 46 (8), 819-24.

(28) Hallock, K. J.; Lee, D. K.; Omnaas, J.; Mosberg, H. I.; Ramamoorthy, A. Membrane composition determines pardaxin's mechanism of lipid bilayer disruption. Biophys. J. 2002, 83 (2), 1004-1013.

(29) Grau-Campistany, A.; Manresa, A.; Pujol, M.; Rabanal, F.; Cajal, Y. Tryptophan-containing lipopeptide antibiotics derived from polymyxin B with activity against Gram positive and Gram negative bacteria. Biochim. Biophys. Acta, Biomembr. 2016, 1858 (2), 333-343.

(30) Lee, D. K.; Brender, J. R.; Sciacca, M. F. M.; Krishnamoorthy, J.; Yu, C. S.; Ramamoorthy, A. Lipid Composition-Dependent Membrane
Fragmentation and Pore-Forming Mechanisms of Membrane Disruption by Pexiganan (MSI-78). Biochemistry 2013, 52 (19), 32543263.

(31) Yorek, M. A. In Phospholipid Handbook; Cevc, G., Ed.; Marcel Dekker: New York, 1993; pp 745-775.

(32) Pozo Navas, B.; Lohner, K.; Deutsch, G.; Sevcsik, E.; Riske, K. A.; Dimova, R.; Garidel, P.; Pabst, G. Composition dependence of vesicle morphology and mixing properties in a bacterial model membrane system. Biochim. Biophys. Acta, Biomembr. 2005, 1716 (1), $40-8$.

(33) Blanchet, C. E.; Spilotros, A.; Schwemmer, F.; Graewert, M. A.; Kikhney, A.; Jeffries, C. M.; Franke, D.; Mark, D.; Zengerle, R; Cipriani, F.; Fiedler, S.; Roessle, M.; Svergun, D. I. Versatile sample environments and automation for biological solution X-ray scattering experiments at the P12 beamline (PETRA III, DESY). J. Appl. Crystallogr. 2015, 48, 431-443.

(34) Franke, D.; Petoukhov, M. V.; Konarev, P. V.; Panjkovich, A.; Tuukkanen, A.; Mertens, H. D. T.; Kikhney, A. G.; Hajizadeh, N. R.; Franklin, J. M.; Jeffries, C. M.; Svergun, D. I. ATSAS 2.8: a comprehensive data analysis suite for small-angle scattering from macromolecular solutions. J. Appl. Crystallogr. 2017, 50, 1212-1225.

(35) Franke, D.; Kikhney, A. G.; Svergun, D. I. Automated acquisition and analysis of small angle X-ray scattering data. Nucl. Instrum. Methods Phys. Res., Sect. A 2012, 689, 52-59.

(36) LeVine, H. Thioflavine-T interaction with synthetic Alzheimersdisease beta-amyloid peptides- detection of amyloid aggregation in solution. Protein Sci. 1993, 2, 404-410.

(37) LeVine, H. Quantification of $\beta$-sheet amyloid fibril structures with thioflavin T. In Methods in Enzymology; Wetzel, R., Ed.; Academic Press: San Diego, 1999; Vol. 309, pp 274-284.

(38) Jones, R. R.; Castelletto, V.; Connon, C. J.; Hamley, I. W. Collagen Stimulating Effect of Peptide Amphiphile $\mathrm{C}_{16}$-KTTKS on Human Fibroblasts. Mol. Pharmaceutics 2013, 10 (3), 1063-1069.

(39) Baral, A.; Roy, S.; Dehsorkhi, A.; Hamley, I. W.; Mohapatra, S.; Ghosh, S.; Banerjee, A. Assembly of an Injectable Noncytotoxic Peptide-Based Hydrogelator for Sustained Release of Drugs. Langmuir 2014, 30 (3), 929-936.

(40) James, S. J.; Slikker, W.; Melnyk, S.; New, E.; Pogribna, M.; Jernigan, $S$. Thimerosal neurotoxicity is associated with glutathione depletion: Protection with glutathione precursors. NeuroToxicology 2005, 26 (1), 1-8.

(41) Karatzas, K. A. G.; Zervos, A.; Tassou, C. C.; Mallidis, C. G.; Humphrey, T. J. Piezotolerant small-colony variants with increased thermotolerance, antibiotic susceptibility, and low invasiveness in a clonal Staphylococcus aureus population. Appl. Environ. Microbiol. 2007, 73, 1873-1881.

(42) Cotter, P. D.; O’Reilly, K.; Hill, C. Role of the glutamate decarboxylase acid resistance system in the survival of Listeria monocytogenes LO28 in low $\mathrm{pH}$ foods. J. Food Prot. 2001, 64, $1362-1368$

(43) Begley, M. I.; Gahan, C. G. M.; Hill, C. Bile Stress Response in Listeria monocytogenes LO28: Adaptation, Cross-Protection, and Identification of Genetic Loci Involved in Bile Resistance. Appl. Environ. Microbiol. 2002, 68, 6005-6012.

(44) Haris, P.; Chapman, D. The Conformational Analysis of Peptides using Fourier Transform IR Spectroscopy. Biopolymers 1995, 37, 251-263.

(45) Pelton, J. T.; McLean, K. R. Spectroscopic methods for analysis of protein secondary structure. Anal. Biochem. 2000, 277, 167-176.

(46) Gaussier, H.; Morency, H.; Lavoie, M. C.; Subirade, M. Replacement of trifluoroacetic acid with $\mathrm{HCl}$ in the hydrophobic purification steps of pediocin PA-1: A structural effect. Appl. Environ. Microbiol. 2002, 68, 4803-4808.

(47) Eker, F.; Griebenow, K.; Schweitzer-Stenner, R. A $\beta_{1-28}$ fragment of the amyloid peptide predominantly adopts a polyproline II conformation in an acidic solution. Biochemistry 2004, 43, 6893-6898.

(48) Susi, H.; Byler, D. M. Resolution-Enhanced Fourier Transfrom Infrared-Spectroscopy of Enzymes. Methods Enzymol. 1986, 130, 290311. 
(49) Adochitei, A.; Drochioiu, G. Rapid characterization of peptide secondary structure by FT-IR spectroscopy. Rev. Roum. Chim. 2011, 56, 783-791.

(50) Glatter, O.; Kratky, O. Small Angle X-ray Scattering; Academic: London, 1982.

(51) Breßler, I.; Kohlbrecher, J.; Thünemann, A. F. SASfit: a tool for small-angle scattering data analysis using a library of analytical expressions. J. Appl. Crystallogr. 2015, 48, 1587-1598.

(52) Kohlbrecher, J.; Bressler, I. SASfit, Software package SASfit for fitting small-angle scattering curves; PSI, 2011.

(53) Creighton, T. E. Proteins: Structures and Molecular Properties;

W.H. Freeman: New York, 1993.

(54) Castelletto, V.; Barnes, R. H.; Karatzas, K.-A.; Edwards-Gayle, C. J. C.; Greco, F.; Hamley, I. W.; Seitsonen, J.; Ruokolainen, J. Restructuring of Lipid Membranes by an Arginine-Capped Peptide Bolaamphiphile. Langmuir 2018, Submitted.

(55) Enoki, T. A.; Moreira-Silva, I.; Lorenzon, E. N.; Cilli, E. M.; Perez, K. R.; Riske, K. A.; Lamy, M. T. Antimicrobial Peptide K0-W6Hyal Induces Stable Structurally Modified Lipid Domains in Anionic Membranes. Langmuir 2018, 34, 2014-2025.

(56) Zweytick, D.; Japelj, B.; Mileykovskaya, E.; Zorko, M.; Dowhan, W.; Blondelle, S. E.; Riedl, S.; Jerala, R.; Lohner, K. N-acylated Peptides Derived from Human Lactoferricin Perturb Organization of Cardiolipin and Phosphatidylethanolamine in Cell Membranes and Induce Defects in Escherichia coli Cell Division. PLoS One 2014, 9 (3), e90228.

(57) Tardieu, A.; Luzzati, V.; Reman, F. C. Structure and Polymorphism of Hydrocarbon Chains of Lipids - Study of LecithinWater Phases. J. Mol. Biol. 1973, 75 (4), 711.

(58) Pabst, G.; Rappolt, M.; Amenitsch, H.; Laggner, P. Structural Information from Multilamellar Liposomes at Full Hydration: Full qRange Fitting with High Quality X-Ray Data. Phys. Rev. E: Stat. Phys., Plasmas, Fluids, Relat. Interdiscip. Top. 2000, 62, 4000-4008.

(59) Caillé, M. Remarques sur la Diffusion des Rayons X dans les Smetiques. C. R. Acad. Sci. Paris 1972, 274, 891-893.

(60) Contreras, L. M.; de Almeida, R. F. M.; Villalain, J.; Fedorov, A.; Prieto, M. Interaction of alpha-melanocyte stimulating hormone with binary phospholipid membranes: Structural changes and relevance of phase behavior. Biophys. J. 2001, 80 (5), 2273-2283.

(61) Berndl, K.; Kas, J.; Lipowsky, R.; Sackmann, E.; Seifert, U. Shape Transformations of Giant Vesicles - Extreme Sensitivity to Bilayer Assimetry. Europhys. Lett. 1990, 13 (7), 659-664.

(62) Farge, E.; Devaux, P. F. Shape Changes of Giant Liposomes Induced by an Asymmetric Transmembrane Distribution of Phospholipids. Biophys. J. 1992, 61 (2), 347-357.

(63) Sackmann, E.; Duwe, H. P.; Engelhardt, H. Membrane Bending Elasticity and its role for Shape Fluctuations and Shape Transformations of Cells and Vesicles. Faraday Discuss. Chem. Soc. 1986, 81, 281.

(64) Svetina, S.; Zeks, B. Membrane Bending Energy and Shape Determination of Phospholipid-Vesicles and Red Blood-Cells. Eur. Biophys. J. 1989, 17 (2), 101-111.

(65) Manges, A. R. Escherichia coli and urinary tract infections: the role of poultry-meat. Clin. Microbiol. Infect. 2016, 22 (2), 122-129.

(66) Paudyal, R.; Barnes, R. H.; Karatzas, K. A. G. A novel approach in acidic disinfection through inhibition of acid resistance mechanisms; Maleic acid-mediated inhibition of glutamate decarboxylase activity enhances acid sensitivity of Listeria monocytogenes. Food Microbiol. 2018, 69, 96-104.

(67) Fiedler, F. Biochemistry of the cell-surface of listeria strains - a locating general view. Infection 1988, 16, S92-S97.

(68) Farber, J. M.; Peterkin, P. I. Listeria-monocytogenes, a foodborne pathogen. Microbiol. Rev. 1991, 55 (3), 476-511.

(69) Karatsa-Dodgson, M.; Wormann, M. E.; Grundling, A. In Vitro Analysis of the Staphylococcus aureus Lipoteichoic Acid Synthase Enzyme Using Fluorescently Labeled Lipids. J. Bacteriol. 2010, 192 (20), 5341-5349. 